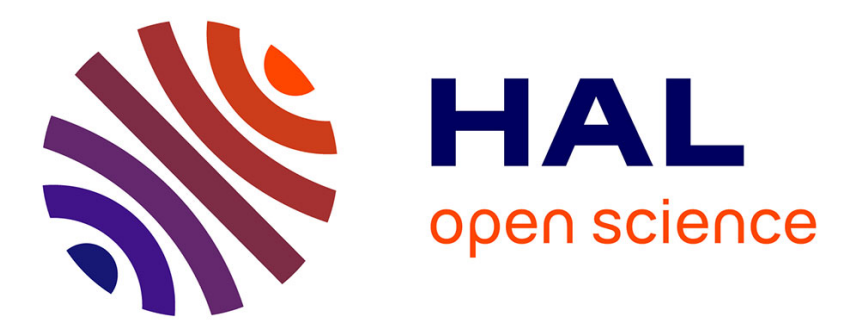

\title{
Air pollution exposure and bladder, kidney and urinary tract cancer risk: A systematic review
}

Mohammad Javad Zare Sakhvidi, Emeline Lequy, Marcel Goldberg, Bénédicte Jacquemin

\section{- To cite this version:}

Mohammad Javad Zare Sakhvidi, Emeline Lequy, Marcel Goldberg, Bénédicte Jacquemin. Air pollution exposure and bladder, kidney and urinary tract cancer risk: A systematic review. Environmental Pollution, 2020, 267, pp.115328. 10.1016/j.envpol.2020.115328 . hal-02961177

HAL Id: hal-02961177 https://hal-univ-rennes1.archives-ouvertes.fr/hal-02961177

Submitted on 8 Oct 2020

HAL is a multi-disciplinary open access archive for the deposit and dissemination of scientific research documents, whether they are published or not. The documents may come from teaching and research institutions in France or abroad, or from public or private research centers.
L'archive ouverte pluridisciplinaire HAL, est destinée au dépôt et à la diffusion de documents scientifiques de niveau recherche, publiés ou non, émanant des établissements d'enseignement et de recherche français ou étrangers, des laboratoires publics ou privés. 
Evidence map of the association between urological cancer and air pollutants. The left panel shows the total number of studies (number of ecological studies between parentheses), color-coded based on number of available studies (from light green for 1 to dark green for 4). The right panel shows, for bladder cancer, the strength of the evidence assessed for each individual studies using the New-Castle Ottowa score (NOS) as y-axis (here we present the average of the NOS by pollutant and outcome, and the line depicts a NOS of 6, our cut-off to define good-quality articles), and for each pair of outcome-pollutant using the GRADE approach.
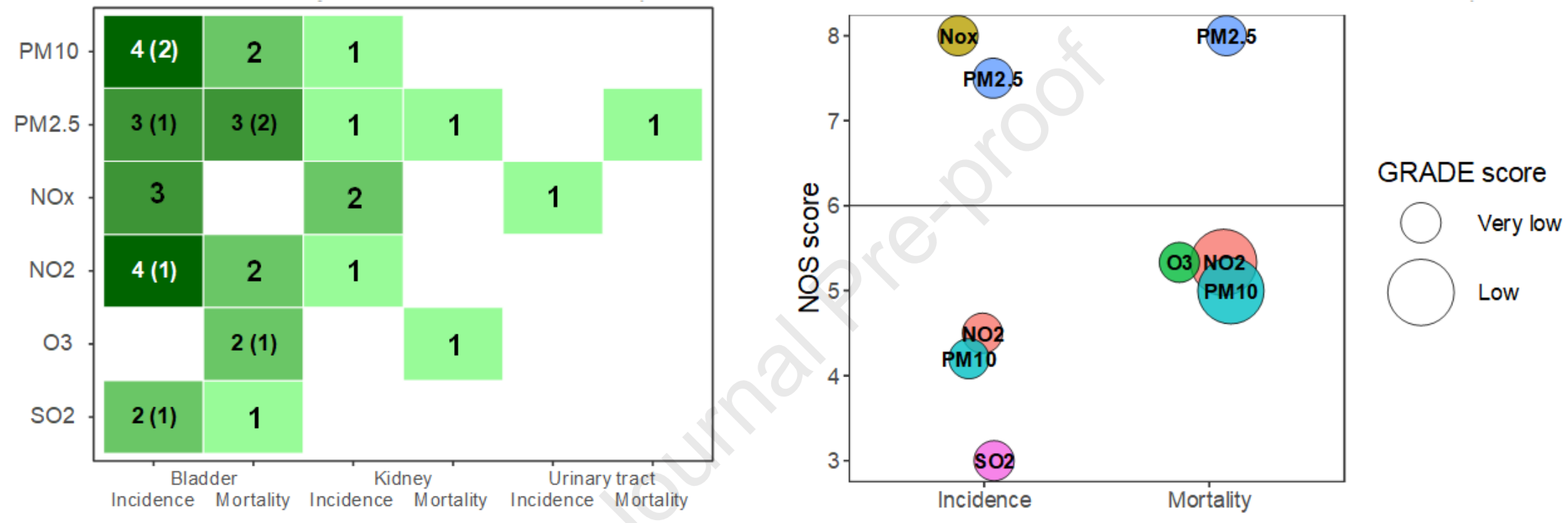

The results of this review showed a suggestive association between kidney and bladder cancer risk and air pollution, however the conclusions are based on few studies and most of them with a low GRADE score. 
1. Air pollution exposure and bladder,

2 kidney and urinary tract cancer risk: a

3 systematic review 
5 Mohammad Javad Zare Sakhvidi ${ }^{\text {a,b }}$; Emeline Lequy ${ }^{\mathrm{c}, \mathrm{d}}$; Marcel

6 Goldberg ${ }^{\mathrm{c}, \mathrm{e}}$; Bénédicte Jacquemin ${ }^{\mathrm{a}}$

7

8

10

11

12

13

14

15

16

17

18

19

20

21

22

23

24

25

26

27

28

29

30

a) Univ Rennes 1, Inserm, EHESP, Irset (Institut de recherche en santé, environnement et travail) - UMR_S 1085, F-35000 Rennes, France

b) Occupational Health Research Center, Shahid Sadoughi University of Medical Sciences, Yazd, Iran

c) INSERM, UMS 011, F-94807 Villejuif, France

d) Université de Montréal Hospital Research Centre (CRCHUM), Montreal, QC, Canada

e) Université Paris Descartes, 12, rue de l'école de médecine, F-75006 Paris, France

Corresponding authors' email: benedicte.jacquemin@inserm.fr 


\section{Abstract}

Background: Exposure to outdoor air pollution has been linked to lung cancer, and suspicion arose regarding bladder, kidney, and urinary tract cancer (urological cancers). However, most of evidence comes from occupational studies; therefore, little is known about the effect of exposure to air pollution on the risk of urological cancers in the general population.

Method: We systematically searched Medline, Scopus, and Web of Science for articles investigating the associations between long-term exposure to air pollution and the risk of urological cancer (incidence or mortality). We included articles using a specific air pollutant $\left(\mathrm{PM}_{10}, \mathrm{PM}_{2.5}, \ldots\right)$ or proxies (traffic, proximity index...). We assessed each study's quality with the Newcastle-Ottawa scale and rated the quality of the body of evidence for each pollutant-outcome with the GRADE approach. The different study methodologies regarding exposure or outcome prevented us to perform a meta-analysis.

Results: twenty articles (four case-control, nine cohort, and seven ecologic) met our inclusion criteria and were included in this review: eighteen reported bladder, six kidney, and two urinary tract. Modeling air pollutants was the most common exposure assessment method. Most of the included studies reported positive $\underline{\text { associations between air pollution and urological cancer risk. However, only a few }}$ reached statistical significance (e.g. for bladder cancer mortality, adjusted oddsratio of $1.13(1.03-1.23)$ for an increase of $4.4 \mu \mathrm{g} . \mathrm{m}-3$ of $\left.\mathrm{PM}_{2.5}\right)$. Most studies inadequately addressed confounding, and cohort studies had an insufficient followup.

Discussion: Overall, studies suggested positive (even though mostly non$\underline{\text { significant) }}$ associations between air pollution exposure and bladder cancer mortality and kidney cancer incidence. We need more studies with better confounding control and longer follow-ups. 
Keywords: Air pollution; Cancer; Mortality; Incidence; Systematic review

\section{Introduction}

61

Sixteen percent of the deaths from non-communicable diseases are attributed to air pollution(1). Exposure to ambient air pollution has been linked to several health

64 outcomes, including incidence and mortality from cardiovascular, respiratory, and cancerous diseases(2-6). Respiratory and cardiovascular effects of air pollution exposure are well demonstrated in both occupational and the general population(7). Most of the available literature on the relationships between air pollution exposure and cancer focused on lung $(8,9)$ and child cancers $(10,11)$, and relied on occupational air pollution exposures(12, 13). In 2013, the International Agency for Research on Cancer (IARC) classified outdoor air pollution as a human carcinogen, based on sufficient evidence especially on lung cancer. The IARC also suggested a positive association for bladder cancer(14). The link between outdoor air pollution exposure and bladder cancer was first reported at the end of the $19^{\text {th }}$ century, based on the findings in a group of workers in the dye industry (15). Later occupational studies revealed that exposure to several air pollutants (such as polycyclic aromatic hydrocarbon (PAHs) and diesel engine exhausts) are linked with an increased risk for bladder cancer(16, 17). However, up to date, new evidence keeps coming out for the general population and other cancer sites including bladder(18-21), kidney $(22,23)$, and urinary $\operatorname{tract}(24,25)$.

The likely shared mechanisms between air pollution and tobacco smoking -an established risk factor for bladder cancer- support the rationale for a link between bladder cancer and air pollution. Excretion of mutagenic metabolites of inhaled air pollutants through the urinary system could also increase the urological system 
cells' exposure to carcinogens(26). However, the concentration of air pollutants in the general environment is considerably lower than in occupational settings, and little is known about the effect of general population exposure to air pollution on the risk of urological cancers.

In this review, we aimed to systematically review the available evidence on longterm exposure to air pollution, and surrogate indices of vehicle emissions, with the risk of bladder, kidney, and urinary tract cancers incidence and mortality.

\section{Materials and Methods}

\section{Search strategy}

This review was conducted according to the Meta-analyses Of Observational Studies in Epidemiology (MOOSE) guidelines(27). We used three databases including Medline, Scopus, and Web of Science (without language restriction) to systematically search for the available literature on the association between longterm exposure to outdoor air pollution (and surrogate indices such as traffic proximity) and bladder, kidney or urinary tract cancer incidence and mortality published until the June $15^{\text {th }}$, 2019. Combination of MeSH and non-MeSH keywords related to outdoor air pollution as the exposure of interest: as exposure, particulate matters with an aerodynamic diameter smaller than 2.5 and 10 micrometers $\left(\mathrm{PM}_{2.5}\right.$ and $\left.\mathrm{PM}_{10}\right)$, sulfur oxides and dioxide $\left(\mathrm{SO}_{\mathrm{x}}\right.$ and $\left.\mathrm{SO}_{2}\right)$, nitrogen oxides and dioxide $\left(\mathrm{NO}_{\mathrm{x}}\right.$ and $\left.\mathrm{NO}_{2}\right)$, ozone $\left(\mathrm{O}_{3}\right)$, carbon monoxide $(\mathrm{CO})$, distance to road, traffic density, and, as the outcome, selected urological cancer incidence and mortality (kidney, bladder, urinary tract and "urinary cancer" in general) were used to search the selected databases (Table S1). We also conducted a manual search 
112 from the reference lists of relevant original studies or reviews to identify any

113 additional documents relevant for this review.

\section{Study selection}

117 After duplicates removal, titles and abstracts were evaluated according to the study 118 inclusion and exclusion criteria by two independent reviewers (M.Z and E.L)

119 (Table S2). The reviewers included all the studies that met these inclusion criteria 120 and reported at least one association between the exposure to one of the air 121 pollutants of interest $\left(\mathrm{PM}_{10}, \mathrm{PM}_{2.5}, \mathrm{NO}_{2}, \mathrm{NO}_{\mathrm{x}}, \mathrm{SO}_{2}, \mathrm{O}_{3}\right)$, or proxies of air pollution exposure, and one of the cancers of interest. In the case of inconsistency between reviewers, the third reviewer (B.J) assessed the eligibility criteria of the study, and then a consensual decision was taken by the three reviewers. Editorials, case reports, reviews, in-vitro, animal studies, as well as studies that reported exclusively the effects of occupational exposure, and indoor air pollutants were excluded. Due to the only recent development of exposure assessment models allowing estimating air pollution at the individual level, we also included studies that used proxies of air pollution exposure such as distance to major roads, traffic,

130 or petrol station densities.

\section{Data extraction}

All relevant data including first author name (as the study ID), publication date, study title, location of study, study design, number of participants and cases,

136 follow-up time (for cohort studies), population of interest, age group and sex of

137 participants, exposure assessment method, type of air pollutant or proxy, type of outcome (mortality or incidence), type of cancer, outcome measurement method, 
statistical method, type of observed exposure-response relationship (if reported), level of adjustment, the point estimate and $95 \%$ confidence intervals (CIs) of crude and adjusted effect size(s) were extracted in a Microsoft Excel sheet.

\section{Quality assessment}

\section{Newcastle-Ottawa Scale (NOS):}

The quality of each selected case-control and cohort study was assessed by the NOS, which was not applicable for ecologic studies $(28,29)$. The NOS is based on eight items distributed in three domains: (i) the selection of study groups, (ii) the comparability of cases and controls (or of exposed and non-exposed participants), and (iii) the ascertainment of exposure/outcome. Using a starring system, all items can earn one star, except the comparability item that can earn up to two stars (first, the studies were checked for adjustment for the minimal required set of a priori defined covariates (here we chose age, sex, occupation, and smoking) and second, they were checked for any further adjustment). The final NOS score of each study sums up the earned stars. We considered studies with exposure assessment via land-use regression or dispersion models linked to residential addresses as a gold standard and highest exposure assessment quality. For cohort studies, a minimum of 10 years was considered a sufficient follow-up time. As we found no universally accepted criterion for the definition of good-quality based on the NOS score, we considered a cut-off score of 6 out of 9 to define good-quality articles. We finally reported the mean NOS score according to the study design and cancer site.

Grading of Recommendations Assessment, Development, and Evaluation system (GRADE): 
We evaluated the overall quality of the evidence using the GRADE system for each pair of exposure-outcome(30). GRADE is a subjective framework yielding a score between "high", "moderate", "low", and "very low". GRADE starts the evaluation by attributing a score from the study design and then uses eight domains to modify this score. GRADE was initially developed for clinical practice recommendations, for which observational studies were considered low-quality. Yet in air pollution epidemiology, nearly all studies are observational; therefore, we adapted the original methodology as follows. As a starting point, we considered the cohort and case-control studies as the sources with high-quality evidence, and cross-sectional and ecologic design studies as sources with low-quality evidence. The original score can upgrade/downgrade according to five downgrading (risk of bias, inconsistency, imprecision, indirectness, and publication bias) and three upgrading domains (dose-response trend, the magnitude of associations, and residual confounding). For the risk of bias, representativeness of population, the origin of controls, inadequate control of confounders, and inadequate follow-up (ten years) were considered. More specifically for the control of confounders, adjustment for major known risk factors of the urinary system cancers such as sex, occupation, age, and smoking was considered necessary to study the possible effect of air pollution. Indeed bladder and kidney cancers are known smoking-related (31-33), and an important proportion of bladder cancer is attributed to occupational exposures(12). Heterogeneity in the effect sizes and non-overlapping of reported confidence intervals were considered as the measures of inconsistency. Imprecision was considered as a small number of studies (less than three) or studies showing associations in the opposite direction for the same pair of exposure/outcome. The accordance of the population, exposure, and outcome of the studies to the targeted population, exposure, and outcome of this review was considered as a measure of indirectness. In this review, deciding about publication 
192 bias was hard due to the impossibility to perform a meta-analysis and lack of

193 funnel plot or relevant statistical tests. Therefore, we could just consider the

194 omission of reporting certain results in the included papers as possible publication

195 bias. Reporting of an effect size above 1.4 (based on the estimates reported in

196 studies on air pollution and cancer) or of a dose-response relationship, as well as

197 the role of residual confounding, were also considered for upgrading. We

198 considered only one type of residual confounding: cases where the exposure

199 misclassification could shift the association towards the null.

Statistical methods used in the included papers

$\underline{\text { Studies reported results of associations (crude and/or adjusted) by odds ratio (OR), }}$ relative risk (RR), the hazard ratio (HR), incidence rate ratio (IRR), or standardized incidence ratio (SIR), and their corresponding CIs. Because of the diversity of outcomes, air pollutants, and study designs, each exposure-outcome pair included at most four articles, and often with different statistical models and measures of association; therefore, we were unable to perform a meta-analysis. Instead, we reported the quantitative outcomes for those exposure-outcome associations that were available in more than one study in a separate table for each site of cancer.

\section{Results}

\section{General characteristics of studies}

216 A total of 2773 items were identified through databases searches (we did not find 217 any non-English paper). We did not find any other articles using other sources. 218 After duplicate removal, we screened titles and abstracts and selected 70 articles 
for full-text evaluation; we excluded 50 articles because they did not meet the inclusion criteria. We found four case-control studies(18-21), nine cohort studies(22-24, 34-39), and seven ecologic studies(25, 40-45), totalizing 20 articles included into this review (Figure 1, Table 1 and Table 2). All of these studies were conducted since 2004, and since 2010 for $85 \%$ ( $n=17)$ of them $(19,20,22-25$, $34,35,37-45)$. Nine studies took place in $\operatorname{Asia}(20,21,24,39-42,44,45)$, nine in Europe $(18,19,22,23,25,34-37)$ and two in North America(38, 43). Five of the Asian studies were ecologic(40-42, 44, 45), with two case-control studies $(20,21)$ and two cohort studies $(24,39)$. European studies included one ecologic study(25), two case-control studies $(18,19)$, and six cohort studies $(22,23,34-37)$. In the casecontrol studies, the number of cases ranged between 680(21) and 1641(20) (sum of cases across all case-control studies: 4478). In the cohort studies, the number of outcomes ranged between 73(22) and 1324(38), with total of 5438 cases across all cohorts.

\section{Quality assessment}

Tables 3 and 4 and Figure 2 report quality scores of the selected cohort and casecontrol studies respectively (as stated in the methods section, the NOS was not applicable for ecologic studies). Pooling all relevant articles, we estimated an average NOS score of 6.58 , which is higher than our cut-off of six which defines good-quality.

The seven cohort studies on bladder cancer earned between 3 and 9 stars and five of them earned a NOS score of six or higher. Exposure and outcome assessment domain was the strongest domain across studies, whereas the adequacy of followup and comparability (in terms of the adequacy of adjustment for confounders) was the weakest domain. The four case-control studies on bladder cancer earned 
between four and six stars (only one study earned six stars). The strongest items in the case-control studies were using the same method of exposure assessment and ascertainment for both cases and controls across studies and also control selection. None of the case-control studies reported a response rate.

The four cohort studies on kidney cancer all earned at least 6 stars (mean NOS score: 7.75), and the two cohort studies on urinary tract cancers earned 7 and 9 stars: they were considered of good-quality with the same weak points as the cohort studies on bladder cancer (follow-up inadequacy and lack of comparability).

\section{GRADE assessment}

The GRADE approach was used to assess the overall quality of the evidence of the nine exposure-outcome pairs that were investigated by two or more studies (all were on bladder cancer risk) (Table S3- S11). In most cases, the level of evidence was very low, except for " $\mathrm{PM}_{10}$ and bladder cancer mortality" and " $\mathrm{NO}_{2}$ and bladder cancer mortality" (Figure 2). The most frequent limitation concerned "indirectness" due to the few numbers of studies for each pair, especially $\mathrm{PM}_{2.5}$ and bladder cancer mortality. The risk of bias was quite high, due to insufficient follow-up time, unclear case definition, imprecise exposure assessment, lack of representativeness, and residual confounding, decreasing the score on the quality of evidence for all exposure-outcome pairs except for bladder cancer incidence and $\mathrm{PM}_{2.5}$. The available evidence for bladder cancer mortality and exposure to $\mathrm{NO}_{2}$ or $\mathrm{PM}_{10}$ was consistent. However, for the other exposure-outcome pairs, we downgraded the evidence quality because of inconsistency. The magnitude of the reported effect size was generally lower than 1.4 (except for $\mathrm{NO}_{2}$ and $\mathrm{PM}_{10}$ with

271 bladder cancer mortality). The lack of sufficient evidence of a dose-response 272 relationship prevented us from upgrading the score in this domain. Potential 
exposure misclassification (as a measure of residual confounding in this review) was observed for all reported exposure-outcome pairs, except NOx exposure and bladder cancer incidence.

\section{Exposure assessment}

Different air pollutants or proxies of air pollution with different quantification approaches were used across the studies (Table 1 and 2; Figure 2). Among classic air pollutants, studies reported results for $\mathrm{PM}_{10}(21-23,25,34,35,42), \mathrm{PM}_{2.5}(19$, $23,35,38,39,44,45), \mathrm{PM}_{2.5}$ absorbance $(23,35)$, organic carbon in PMs $(23,35)$, and elemental composition of PMs $(23,35)$; and for gases $\mathrm{NO}_{\mathrm{x}}(24,35,37)$, $\mathrm{NO}_{2}(19,21,23,34,35,38,40), \mathrm{SO}_{\mathrm{x}}(22), \mathrm{SO}_{2}(21,34,42)$, hydrogen sulfide (22), $\mathrm{O}_{3}(21,38), \mathrm{CO}(21)$, and benzene (34). $\mathrm{NO}_{2}, \mathrm{PM}_{2.5}$, and $\mathrm{PM}_{10}$ were the most used air pollutants across studies (each one reported in seven studies).

Air pollution modeling was the most common method of exposure assessment in the selected studies, whether by dispersion modeling $(22,25,34)$, land-use regression(19, 23, 24, 35, 37-39), remote sensing(40, 45), interpolation(42) and kriging(44). One study used stationary stations measurements of criteria air pollutants at the municipality level(21). Seven studies also reported results for proxies of air pollution such as traffic density, presence of major roads near residential addresses $(19,23,35,36)$, window facing traffic $(18,19)$, type and quantity of traffic, petrol station density near the residential area(20), and annual total waste gas emission at the state level(41). The exposure assessment method was unclear in one study(43).

\section{Reported outcomes}


We considered cancer incidence or mortality separately. Different approaches were used across studies to assess the outcome. Most of the studies used data from national or regional cancer registries(23-25, 34-37, 40-45), however, two casecontrol studies used data from hospital registries $(18,19)$, and five others used death certificates(20-22, 38, 39). Hereafter, we will summarize the evidence on each cancer site (bladder, kidney, and urinary tract), first regarding incidence and then mortality.

\section{Bladder cancer}

Eighteen studies reported bladder cancer incidence and/or mortality data (Table 1), including seven cohort studies $(22,24,34-38)$ with total cancer cases of 3219 , four case-control studies with a total of 4478 cases (18-21), and seven ecologic studies (25, 40-45). Five of the cohort studies(24, 34-37), two of the case-control studies $(18,19)$, and five of the ecologic studies $(25,40-42,45)$ dealt with bladder cancer incidence; six $(20-22,38,43,44)$ (including two cohorts(22, 38), two casecontrols $(20,21)$ and two ecologic studies $(43,44))$ dealt with bladder cancer mortality.

\section{Bladder cancer incidence}

Among 26 associations (excluding correlation coefficients) on five air pollutants (excluding proxies), we found one null and six point-estimates below one, and all the other ones were above one (Table 5). But only three associations reached the statistical significance, for $\mathrm{NO}_{2}$ (34) and $\mathrm{PM}_{2.5}(25)$. Unexpectedly, one of the cohort studies found a higher SIR in the areas with lower traffic intensity score compared to the areas with higher traffic intensity (SIR: 1.16 vs. 0.87)(36). The 
two case-control studies $(18,19)$ - using the same epidemiologic data but different exposure measures $\left(\mathrm{PM}_{2.5}\right.$ and $\mathrm{NO}_{2}(19)$; and windows facing traffic and type and quantity of traffic(18)) - found positive but not significant associations between exposures and bladder cancer incidence, and larger point estimates for nonsmokers and women (but still statistically non-significant). In contrast to these cohorts and case-control studies, four ecologic studies(25, 40, 41, 45) found significant positive associations between at least one air pollution measure and bladder cancer incidence. However, the pollutants of interest in all these studies were different and it was impossible to compare the results.

\section{Bladder cancer mortality}

Among 17 associations on five air pollutants and bladder cancer mortality from non-ecological studies, only one point-estimate was below one, the others were positive (with generally higher point-estimates than for bladder cancer incidence) and actually, six reached statistical significance $(21,25,38)$. Further, Liu et al. (2009) found significant $p$ for trends across tertiles of exposure for $\mathrm{NO}_{2}, \mathrm{SO}_{2}$, and $\mathrm{PM}_{10}$ - although in unadjusted models. When using a pollution index (combining $\mathrm{NO}_{2}$ and $\mathrm{SO}_{2}$ ), they also found a significant $\mathrm{p}$ for trend. When analyzing associations in subgroups of the population, Ancona et al. (22) found a positive and significant association between bladder cancer mortality and hydrogen sulfide exposure in women $(\mathrm{HR}=1.35 ; 95 \% \mathrm{CI}: 1.00-1.82)$; Turner et al (38) reported a significant association with $\mathrm{PM}_{2.5}$ only for men, never smokers and those with at least high school education. In Taiwan $(20,21)$, the case-control studies found a significant positive association between the days with ozone pollution (as a measure of short-term exposure to air pollution) and bladder cancer mortality(21), 
but no association with the density of petrol stations near the residential addresses (20).

Three ecologic studies reported inconsistent results for $\mathrm{PM}_{2.5}$ : a non-significant association(43), a significantly positive association(44), and a significantly negative association(45). Smith et al. also found a significant association between bladder cancer mortality and ozone days(43).

\section{Kidney cancer}

Five studies - including four cohorts $(22,23,37,38)$ and one ecologic study(41) reported associations between kidney cancer and air pollution (Table 2). Two studies $(22,38)$ dealt with kidney cancer mortality and three $(23,37,41)$ with kidney cancer incidence. The two cohort studies $(23,37)$ on kidney cancer incidence included 792 cases. For kidney cancer mortality, the largest study was from "the Cancer Prevention Study-II" with 927 cases (38). Another study was based on the data from 14 European cohorts of the ESCAPE study with 697 kidney cancer incidence cases(23).

\section{Kidney cancer incidence}

The five associations between kidney cancer incidence and three air pollutants were all positive but none reached statistical significance $(37,46)$. One of the two studies investigating NOx reported a point estimate larger than 1.4 (Table 6). The study pooling 14 European cohorts (23) reported heterogeneous findings across cohorts. The ecological study reported a significant positive correlation between waste gas emissions and kidney cancer incidence; the analyses by sex indicted 
379 significant correlations for both men and women with a coefficient of 0.8 for male $380-$ twice as high as for women (41).

\section{Kidney cancer mortality}

384 The two cohort studies on air pollution and kidney cancer mortality $(22,38)$ did not investigate the same air pollutant. Turner et al. (38) found a significant association with $\mathrm{PM}_{2.5}(\mathrm{HR}=1.14 ; 95 \% \mathrm{CI}: 1.03-1.27)$, but not for $\mathrm{NO}_{2}$ or $\mathrm{O}_{3}$. The analyses on subgroups showed that this association was only significant among men and current smokers. Ancona et al. (22) found no significant association between kidney cancer mortality and $\mathrm{NO}_{2}, \mathrm{PM}_{10}$, hydrogen sulfide or $\mathrm{SO}_{\mathrm{X}}$ exposure.

\section{Urinary tract cancer}

Two cohort studies reported associations between air pollution exposure and urinary tract cancer incidence(24) and mortality(39) (Table 2). Both studies found non-significant associations between these outcomes and exposure to selected air pollutants.

\section{Discussion}

402

403 In this study, we reviewed the available body of evidence on the association

404 between the bladder, kidney, and urinary tract cancers incidence and mortality and 
405

air pollution exposure, concluding to a suggestive association between kidney and bladder cancer risk and air pollution.

Indeed, overall five cohorts found small to moderate positive associations especially for bladder and kidney cancer mortality (even mostly non-significant) with different air pollutants exposure. Five out of seven ecological studies found a significant increase in the risk of bladder and kidney cancer incidence and mortality. Evidence on the association between air pollution exposure and kidney cancer seems stronger compared to bladder cancer, as we found proportionally more papers with positive and significant associations even if based on only three studies. Additionally, for bladder cancer, the results on mortality were more suggestive than on incidence. Most of the studies included had an acceptable quality in terms of NOS score, and the weakest point was generally low quality in adjustment and insufficient follow-up time (in the case of cohort studies). In total, the quality of evidence on the associations between air pollutants and bladder cancer was very low or low. The use of different exposure indices, statistical approaches, effect sizes, outcomes, and study designs made it impossible to do a meta-analysis.

The currently available evidence on the association of bladder and kidney cancer incidence and mortality with air pollution exposure comes mostly from occupational environments concerning exposure to gasoline vapors(17), chlorinated solvents $(47,48)$, asbestos(49), pesticides(50) and PAHs (51). A review and meta-analysis found an increased risk of urinary bladder cancer in motor vehicle drivers, who were occupationally exposed to a considerable amount of traffic-related air pollution (52). However, even if the intensity of air pollution exposure in the general population is considerably lower than for the drivers and 
432 industrial workers, considering lifetime exposure in the general population, it is reasonable to suppose that the exposure to air pollution could be associated with an 434 increased risk of urinary tract cancers. Several mechanisms could explain the relationship between exposure to air pollution and urological cancer. For instance, recent animal studies have shown that exposure to $\mathrm{PM}_{2.5}$ can induce angiotensin/bradykinin system imbalance, subsequent early kidney damage and oxidative stress, and/or inflammation, which finally can cause cancer(53). A glomerular filtration rate reduction was also associated to exposure to particulate matters in those living near a major roadway(54) and also in those exposed to particulate matter(55); this reduced glomerular filtration rate could be a predictor of kidney and bladder cancer recurrence and progression(56, 57). These physiological findings suggest that exposure to air pollutants could induce lesions on the urinary system ultimately leading to urological cancers.

One of the main weaknesses of the non-ecological included studies was an inadequate adjustment for confounders. In addition to the main confounding variables described above, several studies have reported an association between environmental tobacco smoke (passive smoking) and kidney(58) and bladder cancer $(59,60)$. Not only not all of the selected papers in our review adjusted their analyses for smoking status, but none of them considered passive smoking exposure. Additionally, ecological studies could not include these variables in their models because of their natural design limitations. The other main weakness of the non-ecological studies was that they did not consider an adequate follow-up time. In addition, another major issue concerns the air pollution exposure assessment: since cancer occurrence is a chronic process, and since the spatial patterns of the environmental stressors may change over the years as well as studies' participants may move, taking a unique exposure value in the analyses may lead to exposure 
misclassification. Considering that for the long-term exposure there is more spatial than temporal variability, taking one value as an exposure poses a problem especially for people moving over time(61). Most of the selected studies do not include information on historic exposures at the individual level. Another important yet seldom addressed the question in the available literature is how long the latency period between air pollution exposure and cancer outcomes should be considered in the statistical analyses. Therefore, because the selected studies used air pollutant exposures that do not necessarily take into account the long latency period between exposure and occurrence of outcomes, the co-occurrence of several environmental exposures, and the historic exposures, their analyses may yield biased risk estimates.

Other limitations of the included studies are the following. Ambient air pollution and noise usually co-occur in the environment(62). Recent studies suggest a possible association between noise exposure and cancer(63, 64). Considering noise exposure, the existence or type of insulation, and opening or closing pattern of windows or time-activity patterns of participants in future studies is advisable. Additionally, the inclusion of the role of indoor air pollution is also worthwhile. Castaño et al. (18) found that living more than 40 years in a city with a population of more than 100,000 was associated with an increased risk for bladder cancer. Exposure to air pollution could be an underlying cause of the urban-rural difference in cancer incidence and mortality. However, other factors such as a different lifestyle and different environmental exposures in rural and urban areas (such as higher noise, or light at night exposures and lower green space access for urban-dwellers) should not be neglected. All of these factors are correlated and could be regarded as underlying factors in the etiology of the cancers. 
487 Different measures of air pollution exposure were reported in the studies selected in this review. Two studies based on the same epidemiologic data, but using either direct air pollution measures or proxies to assess exposure, found similar results: this indicates the comparability of this two exposure assessment approaches. Traffic indicators seem to be a good alternative in the case of data paucity to predict long-term exposure to air pollutants(65). However, proximity models may lead to greater misclassification than models based on direct air pollution measurements, such as land use regression (66). Both approaches are based on the residential addresses of the participants, and relying only on residential addresses can increase the risk of non-differential misclassification. Without knowing the activity pattern of the participants, such as commuting to the workplace, it is not possible to know their precise exposure. Additionally, relying on self-report, as noticed in some studies(18), could introduce further bias. Given the availability of modeling data on air pollutants or traffic measures, the limiting step in the ecologic studies is the spatial resolution of outcome data instead of exposure. For example, in most studies, the exposure data are available in finer resolution (several kilometers'), compared to the outcomes (mostly reported in the level of the region 504 or district).

Strengths and limitations

To our knowledge, this is the first systematic review on the association between air

510 pollution exposure in the general population and bladder, kidney, and urinary tract 511 cancer incidence and mortality. We found only one review on the associations 512 between exposure to particulate matters and urological cancers in the general 
population (67). However, it was not a systematic but narrative review, which

514 focused only on PM. Moreover, more than half of the studies included in our review have been published between 2015 and 2019, whereas the previous one included articles up to 2017: therefore an updated review of the evidence seemed useful necessary. In this review, we collected evidence from all types of study design and using different direct and indirect air pollution exposure metrics. Another strength of our review is that we encompassed both incidence and mortality evidence, which could give a broader insight into the possible associations between air pollution and urologic cancer. Using a strict quality assessment tool made it possible to compare the quality of the studies. However, our study suffers from several limitations. First of all, due to huge heterogeneity in the exposure metrics, study design, type of outcomes, and cancers and reported effect sizes, it was impossible to do a meta-analysis. We also were unable to detect publication bias in our study objectively. Additionally, nearly one-third of the selected studies were ecologic in design, and we were unaware of the standard and applicable instrument to measure and rank the quality across ecologic studies.

\section{Conclusion}

532 The results of this review showed a suggestive association between kidney and

533 bladder cancer risk and air pollution. However, the diversity of outcomes, air 534 pollutants, and study designs prevented us to conduct a meta-analysis, and 535 furthermore, we identified several major shortcomings in many studies. Therefore, 536 the results of our review could be used in the conduction and design of future 537 studies for the assessment of the associations between ambient air pollution and 538 cancer especially bladder and kidney cancer. Future studies should consider a 
more comprehensive adjustment, and more accurate exposure assessment and ascertainment methods.

\section{Funding}

This study was supported by the ARC Foundation which funded the OCAPOL study (A longitudinal observatory of the effects of chronic exposure to outdoor air pollution on cancer risk) within the framework of the CANC'AIR call (CANCAIR201501234).

\section{Role of the funding source}

The study funder did not contribute to the study design, data collection, data analysis, data interpretation, or writing of this manuscript. The corresponding author had full access to all the data used in this study and had final responsibility for the decision to submit for publication.

\section{Contributors}

MZ, EL, and BJ contributed to the study design. MZ and EL did the evidence screening. BJ contributed to the selection of papers with no-consensus by MZ and EL. MZ took the lead in drafting the manuscript. All authors contributed to the interpretation of data, provided critical revisions to the manuscript, and approved the final draft.

\section{Declaration of Competing Interest}


566 We declare no competing interest. 


\section{References}

568 1. World Health Organization. Ambient air pollution: A global assessment of exposure and burden of disease. 2016.

570 cancer incidence and ambient air pollution in China: cancer incidence and ambient air pollution in China: a spatiotemporal analysis. Environmental research. 2016;144:60-5.

3. Turner MC, Krewski D, Diver WR, Pope III CA, Burnett RT, Jerrett M, et al. Ambient air pollution and cancer mortality in the cancer prevention study II. Environmental health perspectives. 2017;125(8):087013.

4. Tie X, Wu D, Brasseur GJAE. Lung cancer mortality and exposure to atmospheric aerosol particles in Guangzhou, China. Atmospheric environment. 2009;43(14):2375-7.

5. Pope III CA, Burnett RT, Thun MJ, Calle EE, Krewski D, Ito K, et al. Lung cancer, cardiopulmonary mortality, and long-term exposure to fine particulate air pollution. JAMA. 2002;287(9):1132-41.

6. Pope III CA, Turner MC, Burnett RT, Jerrett M, Gapstur SM, Diver WR, et al. Relationships between fine particulate air pollution, cardiometabolic disorders, and cardiovascular mortality. Circulation Research. 2015;116(1):108-15.

7. Cohen AJ, Brauer M, Burnett R, Anderson HR, Frostad J, Estep K, et al. Estimates and 25-year trends of the global burden of disease attributable to ambient air pollution: an analysis of data from the Global Burden of Diseases Study 2015. the Lancet. 2017;389(10082):1907-18. 8. Santibáñez-Andrade M, Quezada-Maldonado EM, Osornio-Vargas Á, Sánchez-Pérez Y, García-Cuellar CMJEP. Air pollution and genomic instability: the role of particulate matter in lung carcinogenesis. Environmental pollution. 2017;229:412-22.

9. Raaschou-Nielsen O, Beelen R, Wang M, Hoek G, Andersen Z, Hoffmann B, et al. Particulate matter air pollution components and risk for lung cancer. Environment international. 2016;87:66-73.

10. Shmuel S, White AJ, Sandler DPJEr. Residential exposure to vehicular traffic-related air pollution during childhood and breast cancer risk. Environmental research. 2017;159:257-63.

11. Pacitto A, Stabile L, Viana M, Scungio M, Reche C, Querol X, et al. Particle-related exposure, dose and lung cancer risk of primary school children in two European countries. Science of the total environment. 2018;616:720-9.

12. Antoni S, Ferlay J, Soerjomataram I, Znaor A, Jemal A, Bray FJEu. Bladder cancer incidence and mortality: a global overview and recent trends. European eurology. 2017;71(1):96-108.

13. Brown T, Slack R, Rushton L, cancer wtBOCBSGJBjo. Occupational cancer in Britain: Urinary tract cancers: bladder and kidney. British journal of cancer. 2012;107(Suppl 1):S76.

14. Internation Agency for Research on Cancer. IARC Monographs on the Evaluation of Carcinogenic Risks to Humans 2013;109.

15. Dietrich H, Dietrich BJWjou. Ludwig Rehn (1849-1930)-pioneering findings on the aetiology of bladder tumours. World journal of urology. 2001;19(2):151-3.

16. Boffetta P, Silverman DTJE. A meta-analysis of bladder cancer and diesel exhaust exposure. Epidemiology. 2001:125-30.

17. Latifovic L, Villeneuve PJ, Parent MÉ, Johnson KC, Kachuri L, Group CCRE, et al. Bladder cancer and occupational exposure to diesel and gasoline engine emissions among Canadian men. Cancer mediciene. 2015;4(12):1948-62. 

pollution and risk of urinary bladder cancer in a case-control study in Spain. Occupational and environmental medicine. 2008;65(1):56-60. 19. Turner MC, Gracia-Lavedan E, Cirac M, Castano-Vinyals G, Malats N, Tardon A, et al. Ambient air pollution and incident bladder cancer risk: Updated analysis of the Spanish Bladder Cancer Study. International journal of cancer. 2019.

618 20. Ho CK, Peng CY, Yang CY. Traffic air pollution and risk of death from bladder cancer in 619 Taiwan using petrol station density as a pollutant indicator. Journal of toxicology and 620 environmental health Part A. 2010;73(1):23-32.

621 21. Liu CC, Tsai SS, Chiu HF, Wu TN, Chen CC, Yang CY. Ambient exposure to criteria air 622 pollutants and risk of death from bladder cancer in Taiwan. Inhalation toxicology. $6232009 ; 21(1): 48-54$.

624 22. Ancona C, Badaloni C, Mataloni F, Bolignano A, Bucci S, Cesaroni G, et al. Mortality 625 and morbidity in a population exposed to multiple sources of air pollution: A retrospective cohort study using air dispersion models. Environmental research. 2015; 137:467-74.

23. Raaschou-Nielsen O, Pedersen M, Stafoggia M, Weinmayr G, Andersen ZJ, Galassi C, et al. Outdoor air pollution and risk for kidney parenchyma cancer in 14 European cohorts. International journal of cancer. 2017;140(7):1528-37.

24. Cohen G, Levy I, Yuval, Kark JD, Levin N, Witberg G, et al. Chronic exposure to trafficrelated air pollution and cancer incidence among 10,000 patients undergoing percutaneous coronary interventions: A historical prospective study. European journal of preventive cardiology. 2018;25(6):659-70.

25. Radespiel-Troger M, Geiss K, Twardella D, Maier W, Meyer M. Cancer incidence in urban, rural, and densely populated districts close to core cities in Bavaria, Germany. International archives of occupational and environmental health. 2018;91(2):155-74.

26. Hansen AM, Wallin H, Binderup ML, Dybdahl M, Autrup H, Loft S, et al. Urinary 1hydroxypyrene and mutagenicity in bus drivers and mail carriers exposed to urban air pollution in Denmark. Mutation research/genetic toxicology and environmental mutagenesis. 2004;557(1):7-17.

27. Stroup DF, Berlin JA, Morton SC, Olkin I, Williamson GD, Rennie D, et al. Metaanalysis of observational studies in epidemiology: a proposal for reporting. JAMA. 2000;283(15):2008-12.

28. Hartling L, Hamm M, Milne A, Vandermeer B, Santaguida PL, Ansari M, et al. Validity and inter-rater reliability testing of quality assessment instruments. Methods research reports. 2012 .

29. Stang AJEjoe. Critical evaluation of the Newcastle-Ottawa scale for the assessment of the quality of nonrandomized studies in meta-analyses. European journal of epidemiology. 2010;25(9):603-5.

30. Swiglo BA, Murad MH, Schunemann HJ, Kunz R, Vigersky RA, Guyatt GH, et al. A case for clarity, consistency, and helpfulness: state-of-the-art clinical practice guidelines in endocrinology using the grading of recommendations, assessment, development, and evaluation system. The journal of clinical endocrinology \& metabolism. 2008;93(3):666-73.

31. Freedman ND, Silverman DT, Hollenbeck AR, Schatzkin A, Abnet CCJJ. Association between smoking and risk of bladder cancer among men and women. JAMA. 2011;306(7):73745 .

32. Kiriluk KJ, Prasad SM, Patel AR, Steinberg GD, Smith ND, editors. Bladder cancer risk from occupational and environmental exposures. Urologic oncology: seminars and original investigations; 2012: Elsevier. 
660

661

662

663

664

665

666

667

668

669

670

671

672

673

674

675

676

677

678

679

680

681

682

683

684

685

686

687

688

689

690

691

692

693

694

695

696

697

698

699

700

701

702

703

704

705

33. Sasco A, Secretan M, Straif KJLc. Tobacco smoking and cancer: a brief review of recent epidemiological evidence. Lung cancer. 2004;45:S3-S9.

34. Collarile P, Bidoli E, Barbone F, Zanier L, Del Zotto S, Fuser S, et al. Residence in Proximity of a Coal-Oil-Fired Thermal Power Plant and Risk of Lung and Bladder Cancer in North-Eastern Italy. A Population-Based Study: 1995-2009. International journal of environmental research and public health. 2017;14(8).

35. Pedersen M, Stafoggia M, Weinmayr G, Andersen ZJ, Galassi C, Sommar J, et al. Is There an Association Between Ambient Air Pollution and Bladder Cancer Incidence? Analysis of 15 European Cohorts. European urology focus. 2018;4(1):113-20.

36. Visser $O$, van Wijnen JH, van Leeuwen FE. Residential traffic density and cancer incidence in Amsterdam, 1989-1997. Cancer causes \& control : CCC. 2004;15(4):331-9.

37. Raaschou-Nielsen O, Andersen ZJ, Hvidberg M, Jensen SS, Ketzel M, Sorensen M, et al. Air pollution from traffic and cancer incidence: a Danish cohort study. Environmental health : a global access science source. 2011;10:67.

38. Turner MC, Krewski D, Diver WR, Pope CA, 3rd, Burnett RT, Jerrett M, et al. Ambient Air Pollution and Cancer Mortality in the Cancer Prevention Study II. Environmental health perspectives. 2017;125(8):087013.

39. Wong CM, Tsang H, Lai HK, Thomas GN, Lam KB, Chan KP, et al. Cancer Mortality Risks from Long-term Exposure to Ambient Fine Particle. Cancer epidemiology, biomarkers \& prevention. 2016;25(5):839-45.

40. Al-Ahmadi K, Al-Zahrani A. NO(2) and cancer incidence in Saudi Arabia. International journal of environmental research and public health. 2013;10(11):5844-62.

41. Cong X. Air pollution from industrial waste gas emissions is associated with cancer incidences in Shanghai, China. Environmental science and pollution research international. 2018;25(13):13067-78.

42. Eitan O, Yuval, Barchana M, Dubnov J, Linn S, Carmel Y, et al. Spatial analysis of air pollution and cancer incidence rates in Haifa Bay, Israel. The Science of the total environment. 2010;408(20):4429-39.

43. Smith ND, Prasad SM, Patel AR, Weiner AB, Pariser JJ, Razmaria A, et al. Bladder Cancer Mortality in the United States: A Geographic and Temporal Analysis of Socioeconomic and Environmental Factors. The Journal of urology. 2016; 195(2):290-6.

44. Yeh HL, Hsu SW, Chang YC, Chan TC, Tsou HC, Chang YC, et al. Spatial Analysis of Ambient PM2.5 Exposure and Bladder Cancer Mortality in Taiwan. International journal of environmental research and public health. 2017;14(5).

45. Wang H, Gao Z, Ren J, Liu Y, Chang LT, Cheung K, et al. An urban-rural and sex differences in cancer incidence and mortality and the relationship with PM2.5 exposure: An ecological study in the southeastern side of Hu line. Chemosphere. 2019;216:766-73.

46. Raaschou-Nielsen O, Pedersen M, Stafoggia M, Weinmayr G, Andersen ZJ, Galassi C, et al. Outdoor air pollution and risk for kidney parenchyma cancer in 14 European cohorts. International journal of cancer. 2017;140(7):1528-37.

47. Buhagen M, Grønskag A, Ragde SF, Hilt B. Association between kidney cancer and occupational exposure to trichloroethylene. Journal of occupational and environmental medicine. 2016;58(9):957-9.

48. Purdue MP, Stewart PA, Friesen MC, Colt JS, Locke SJ, Hein MJ, et al. Occupational exposure to chlorinated solvents and kidney cancer: a case-control study. Occupational and environmental mediciene. 2017;74(4):268-74. 
49. Peters CE, Parent M-É, Harris SA, Kachuri L, Latifovic L, Bogaert L, et al. Workplace exposure to asbestos and the risk of kidney cancer in Canadian men. Canadian journal of public health.2018;109(4):464-72.

50. Koutros S, Silverman DT, Alavanja MC, Andreotti G, Lerro CC, Heltshe S, et al. Occupational exposure to pesticides and bladder cancer risk. International journal of epidemiology. 2015;45(3):792-805.

51. Boffetta P, Jourenkova N, Gustavsson PJCC, Control. Cancer risk from occupational and environmental exposure to polycyclic aromatic hydrocarbons. Cancer causes \& control. 1997;8(3):444-72.

52. Manju L, George PS, Mathew. Urinary bladder cancer risk among motor vehicle drivers: a meta-analysis of the evidence, 1977-2008. Asian pacific journal of cancer prevention. 2009;10(2):287-94.

53. Aztatzi-Aguilar O, Uribe-Ramírez M, Narváez-Morales J, De Vizcaya-Ruiz A, Barbier OJP, toxicology $f$. Early kidney damage induced by subchronic exposure to PM 2.5 in rats. Particle and fibre toxicology. 2016;13(1):68.

54. Lue S-H, Wellenius GA, Wilker EH, Mostofsky E, Mittleman MAJJECH. Residential proximity to major roadways and renal function. Journal of epidemiology and community health. 2013;67(8):629-34.

55. Mehta AJ, Zanobetti A, Bind M-AC, Kloog I, Koutrakis P, Sparrow D, et al. Long-term exposure to ambient fine particulate matter and renal function in older men: the veterans administration normative aging study. Environmental health perspectives. 2016;124(9):135360 .

56. Rausch S, Hennenlotter J, Todenhöfer T, Aufderklamm S, Schwentner C, Sievert K-D, et al.. Impaired estimated glomerular filtration rate is a significant predictor for non-muscleinvasive bladder cancer recurrence and progression-Introducing a novel prognostic model for bladder cancer recurrence. Urologic oncology: seminars and original investigations; 2014 : Elsevier.

57. Iff S, Craig JC, Turner R, Chapman JR, Wang JJ, Mitchell P, et al. Reduced estimated GFR and cancer mortality. American journal of kidney diseases. 2014;63(1):23-30.

58. Theis RP, Grieb SMD, Burr D, Siddiqui T, Asal NR. Smoking, environmental tobacco smoke, and risk of renal cell cancer: a population-based case-control study. BMC cancer. 2008;8(1):387.

59. Yan H, Ying Y, Xie H, Li J, Wang X, He L, et al. Secondhand smoking increases bladder cancer risk in nonsmoking population: a meta-analysis. Cancer management and research. 2018; $10: 3781$.

60. Tao L, Xiang Y-B, Wang R, Nelson HH, Gao Y-T, Chan KK, et al. Environmental tobacco smoke in relation to bladder cancer risk-the Shanghai bladder cancer study. Cancer epidemiology and prevention biomarkers. 2010;19(12):3087-95.

61. Shekarrizfard M, Faghih-Imani A, Hatzopoulou MJEr. An examination of population exposure to traffic related air pollution: Comparing spatially and temporally resolved estimates against long-term average exposures at the home location. Environmental research. 2016;147:435-44.

62. Davies HW, Vlaanderen J, Henderson S, Brauer M. Correlation between co-exposures to noise and air pollution from traffic sources. Occupational and environmental medicine. 2009;66(5):347-50.

63. Roswall N, Raaschou-Nielsen O, Ketzel M, Overvad K, Halkjaer J, Sørensen MJCC, et al. Modeled traffic noise at the residence and colorectal cancer incidence: a cohort study. Cancer causes \& control. 2017;28(7):745-53. 
64. Roswall N, Bidstrup PE, Raaschou-Nielsen O, Jensen SS, Overvad K, Halkjar J, et al. Residential road traffic noise exposure and colorectal cancer survival-A Danish cohort study.

756 PloS one. 2017;12(10):e0187161.

65. Brauer $M$, Hoek $G$, van Vliet $P$, Meliefste $K$, Fischer $P$, Gehring $U$, et al. Estimating long-term average particulate air pollution concentrations: application of traffic indicators and geographic information systems. Epidemiology. 2003:228-39. 66. Ryan PH, LeMasters GK, Biswas P, Levin L, Hu S, Lindsey M, et al. A comparison of proximity and land use regression traffic exposure models and wheezing in infants. Environmental health perspectives. 2006;115(2):278-84. 67. Kim, Eun-A. Particulate matter (fine particle) and urologic diseases. International neurourology journal. 2017; 21(03): 155-162. 


\section{List of Figures}

Figure 1. PRISMA flow diagram for the systematic review of the association between air pollution exposure and the risk of selected urological cancers.

Figure 2. Evidence map of the association between urological cancer and air pollutants. The left panel shows the total number of studies (number of ecological studies between parentheses), color-coded based on the number of available studies (from light green for 1 to dark green for 4). The right panel shows, for bladder cancer, the strength of the evidence assessed for each studies using the NOS score as y-axis (here we present the average of the NOS score by pollutant and outcome, and the line depicts a NOS score of 6, our cut-off to define good-quality articles), and for each pair of outcome-pollutant using the GRADE approach.

\section{List of Tables}

Table 1. Summary of finding for the association between exposure to air pollution and bladder cancer risk

Table 2. Summary of finding for the association between exposure to air pollution and kidney and urinary system cancer risk

Table 3. Newcastle-Ottawa Scale (NOS) score for the cohort studies on the association between air pollution exposure and bladder, kidney, and urinary cancer risk

Table 4. Newcastle-Ottawa Scale (NOS) score for the case-control studies on the association between air pollution exposure and bladder, kidney, and urinary cancer risk

Table 5. Reported associations between exposure to outdoor air pollution exposure and bladder cancer risk

Table 6. Reported associations between exposure to outdoor air pollution exposure and kidney and urinary cancer risk

\section{List of supplement Tables}

Table S1. The sample search algorithm used for literature search on outdoor air pollution exposure (as an exposure) and selected urological cancer incidence and/or mortality (as an outcome) on PubMed (https://www.ncbi.nlm.nih.gov/pubmed/). Last updated on June 15, 2019.

Table S2. Inclusion and exclusion criteria based on PECOS (population, exposure, comparison, outcome and study type) for a systematic review on the association between outdoor air pollution exposure and risk of selected urological cancers 
814 Table S3: GRADE assessment for the association between exposure to $\mathrm{PM}_{10}$ and risk of bladder 815 cancer incidence

816

Table S11: GRADE assessment for the association between exposure to $\mathrm{O}_{3}$ and risk of bladder cancer mortality

Table S4: GRADE assessment for the association between exposure to $\mathrm{PM}_{10}$ and bladder cancer mortality

Table S5: GRADE assessment for the association between exposure to $\mathrm{PM}_{2.5}$ and risk of bladder cancer incidence

Table S6: GRADE assessment for the association between exposure to $\mathrm{PM}_{2.5}$ and bladder cancer mortality

Table S7: GRADE assessment for the association between exposure to $\mathrm{NO}_{2}$ and risk of bladder cancer incidence

Table S8: GRADE assessment for the association between exposure to $\mathrm{NO}_{2}$ and risk of bladder cancer mortality

Table S9: GRADE assessment for the association between exposure to $\mathrm{NO}_{\mathrm{x}}$ and risk of bladder cancer incidence

Table S10: GRADE assessment for the association between exposure to $\mathrm{SO}_{2}$ and risk of bladder cancer incidence 
841 Figure 1. PRISMA flow diagram for the systematic review on the association between air 842 pollution exposure and the risk of selected urological cancers.

843

Records identified through database searching $(n=2773)$

Records after duplicates removed ( $n=2034$ )

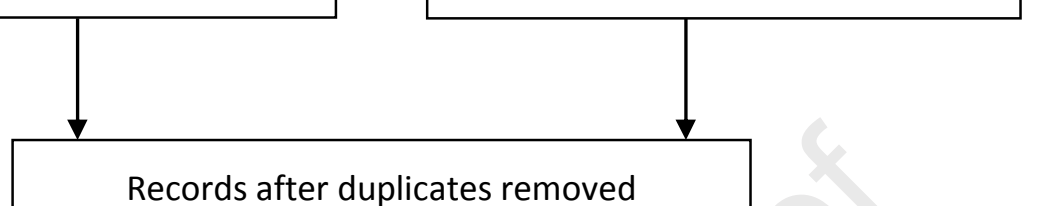
through other sources
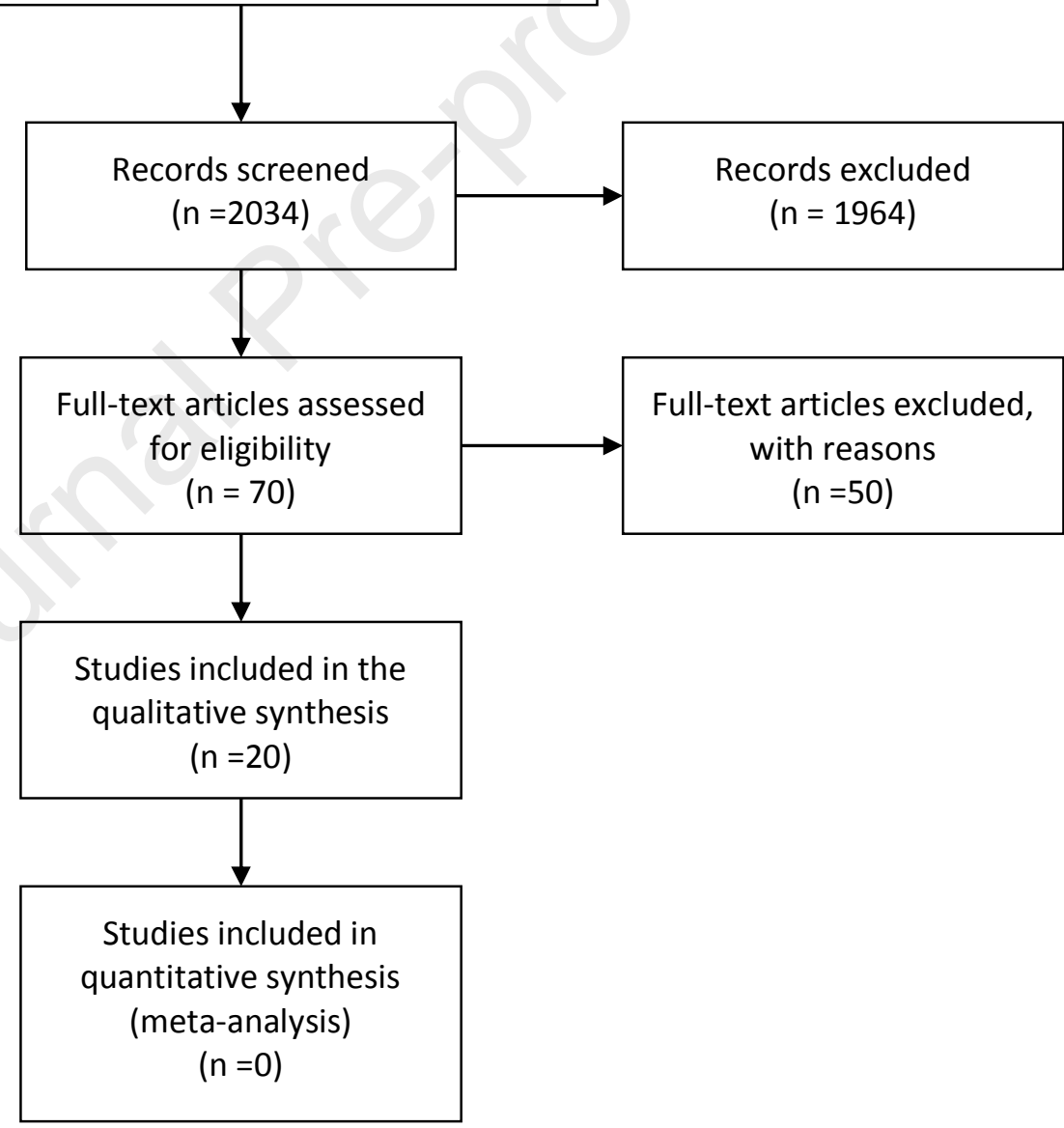
Figure 2. Evidence map of the association between urological cancer and air pollutants. The left panel shows the total number of studies (number of ecological studies between parentheses), color-coded based on the number of available studies (from light green for 1 to dark green for 4). The right panel shows, for bladder cancer, the strength of the evidence assessed for each studies using the NOS score as y-axis (here we present the average of the NOS score by pollutant and outcome, and the line depicts a NOS score of 6 , our cut-off to define good-quality articles), and for each pair of outcome-pollutant using the GRADE approach.
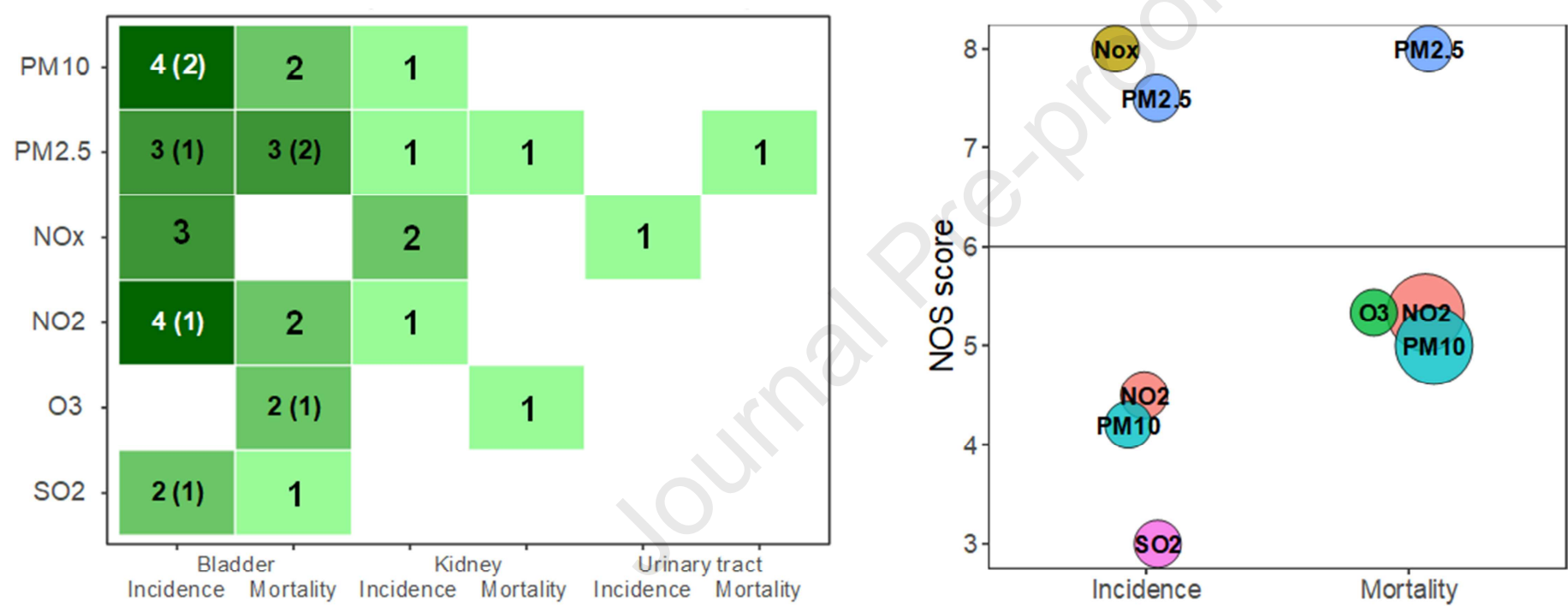

GRADE score 
882 Table 1. Summary of findings for the association between exposure to air pollution and bladder cancer risk

\begin{tabular}{|c|c|c|c|}
\hline $\begin{array}{l}\text { First } \\
\text { author(year); }\end{array}$ & $\begin{array}{l}\text { Design; number } \\
\text { cases/outcomes }\end{array}$ & of Case definition & $\begin{array}{l}\text { Exposure } \\
\text { and metrics }\end{array}$ \\
\hline
\end{tabular}

author(year);
study location

Turner et

(2019); Spain

al. Case-control (case: 938)

(histologically

confirmed hospital

LUR $\quad\left(\mathrm{PM}_{25} ; \quad \mathrm{NO}_{2}\right) ;$ Age group, sex, region, smoking,

No clear association either for ambient $\mathrm{PM}_{2.5}$ or cases)

windows facing a street high-risk occupations

$\mathrm{NO}_{2}$. No evidence for a trend.

Wang et

al. Ecologic study

(2019); China

with traffic (including

number of traffic lanes

and traffic intensity)

Cong et al. Ecologic study

(2018); China

mortality

and Remote sensing $\left(\mathrm{PM}_{2.5}\right) \quad$ Unclear

registry and mortality

data)

Incidence (cancer

registry)

Annual waste gas Sex, number of doctors per and bladder cancer incidence, but a negative association for bladder cancer mortality.

ons (total volume of waste gas, industrial waste gas, other waste

Engel's coefficient

emission and bladder cancer incidence trend.

The gender-specific analysis was only significant for men.

Cohen et al. Cohort (outcome: 74)

(2018); Israel

Collarile et al. Cohort (outcome: 650)

(2017); Italy

Radespiel-Troger Ecologic study

et al. (2017)

Germany

Pedersen et al. 15 prospective (outcome: 943)
Sex, smoking, neighborhood A non-significant and small positive association socioeconomic status, ethnicity, was found. The effect size did not change after hypertension, diabetes, chronic adjustment.

heart and renal

hemoglobin levels

Incidence (cancer Dispersion model $\left(\mathrm{C}_{6} \mathrm{H}_{6}\right.$, Unclear registry) $\quad \mathrm{NO}_{2}, \mathrm{PM}_{10}, \mathrm{SO}_{2}$ )

Incidence registry)

(Cancer Dispersion model $\left(\mathrm{PM}_{10}\right)$

Age, deprivation, age-adjusted lung cancer and chronic liver disease mortality rate

(cancer LUR $\left(\mathrm{PM}_{10} ; \mathrm{PM}_{2.5} ; \mathrm{PM}_{2.5}\right.$ Age, sex, calendar time; smoking, absorbance; $\mathrm{NO}_{2} ; \quad \mathrm{NO}_{\mathbf{x}} ;$ occupation, employment,
Only in women aged 75 years or older the risk increased by increasing exposure to benzene and $\mathrm{NO}_{2}$. The associations for $\mathrm{PM}_{10}$ or $\mathrm{SO}_{2}$ were not linear.

A significant positive association between $\mathrm{PM}_{10}$ exposure and bladder cancer in both sexes. The relative risk in males was lower than females. registry) 


\begin{tabular}{|c|c|c|c|c|c|}
\hline $\begin{array}{l}\text { First } \\
\text { author(year); } \\
\text { study location }\end{array}$ & $\begin{array}{l}\text { Design; number of } \\
\text { cases/outcomes }\end{array}$ & Case definition & $\begin{array}{l}\text { Exposure assessment } \\
\text { and metrics }\end{array}$ & Adjustment & Findings \\
\hline (2016); Europe & & & $\begin{array}{l}\text { traffic intensity on the } \\
\text { nearest street; different } \\
\text { PM elements; organic } \\
\text { carbon in PM) }\end{array}$ & $\begin{array}{l}\text { education; area-level socio- } \\
\text { economic status }\end{array}$ & \\
\hline $\begin{array}{ll}\text { Al-Ahmadi } & \text { et al. } \\
(2013) ; & \text { Saudi } \\
\text { Arabia } & \end{array}$ & Ecologic study & $\begin{array}{l}\text { Incidence } \\
\text { registry) }\end{array}$ & Remote sensing $\left(\mathrm{NO}_{2}\right)$ & Unclear & $\begin{array}{l}\text { A significant association for } \mathrm{NO}_{2} \text { in the ordinary } \\
\text { least square regression model, but not in the } \\
\text { geographically weighted regression model. }\end{array}$ \\
\hline $\begin{array}{l}\text { Raaschou-Nielsen } \\
\text { et al. (2011); } \\
\text { Europe }\end{array}$ & Cohort (outcome: 221) & $\begin{array}{l}\text { Incidence } \\
\text { registry) }\end{array}$ & $\begin{array}{l}\text { LUR }\left(\mathrm{NO}_{\mathrm{x}}\right) \text {, presence of a } \\
\text { major road within } 50 \mathrm{~m}\end{array}$ & Smoking, education, occupation & $\begin{array}{l}\text { A weak non-significant association for traffic- } \\
\text { related air pollution and living near roads. } \\
\text { Adjustment for potential confounders decreased } \\
\text { the risk. }\end{array}$ \\
\hline $\begin{array}{l}\text { Eitan et al. } \\
(2010) \text {; Israel }\end{array}$ & Ecologic study & $\begin{array}{l}\text { Incidence } \\
\text { registry) }\end{array}$ & $\begin{array}{l}\text { Spatially interpolated the } \\
\text { monitoring data }\left(\mathrm{SO}_{2} \text {; }\right. \\
\left.\mathrm{PM}_{10}\right)\end{array}$ & Unclear & $\begin{array}{l}\text { No increase in the risk neither for } \mathrm{PM}_{10} \text { nor for } \\
\mathrm{SO}_{2} \text {. }\end{array}$ \\
\hline $\begin{array}{l}\text { Castano-Vinyals } \\
\text { et al. (2008); } \\
\text { Spain }\end{array}$ & Case-control (case:1219) & $\begin{array}{l}\text { Incidence } \\
\text { (histologically } \\
\text { confirmed hospital } \\
\text { cases) }\end{array}$ & $\begin{array}{l}\text { Proximity to industries, } \\
\text { windows facing traffic, } \\
\text { size of the city of } \\
\text { residence, type and } \\
\text { quantity of traffic }\end{array}$ & $\begin{array}{l}\text { Age, sex, region, smoking, } \\
\text { occupation, consumption of fruits } \\
\text { and vegetables; exposure to } \\
\text { disinfection by-products in water }\end{array}$ & $\begin{array}{l}\text { No association for having windows facing a } \\
\text { street with traffic, number of traffic lanes, traffic } \\
\text { intensity, or living in proximity to industry. } \\
\text { Associations were stronger among non-smokers } \\
\text { and women (non-significant difference). }\end{array}$ \\
\hline $\begin{array}{l}\text { Visser et al. } \\
(2004) \text {; The } \\
\text { Netherland }\end{array}$ & Cohort (outcome: 151) & $\begin{array}{l}\text { Incidence } \\
\text { registry) }\end{array}$ & $\begin{array}{l}\text { Daily traffic intensity } \\
\text { score }\end{array}$ & Unclear & $\begin{array}{l}\text { The standardized incidence rate in areas with } \\
\text { lower traffic intensity score was higher. }\end{array}$ \\
\hline $\begin{array}{l}\text { Turner et al. } \\
\text { (2017); USA }\end{array}$ & Cohort (outcome:1324) & $\begin{array}{l}\text { Mortality (cause of } \\
\text { death from a } \\
\text { questionnaire) }\end{array}$ & $\operatorname{LUR}\left(\mathrm{PM}_{2.5} ; \mathrm{NO}_{2} ; \mathrm{O}_{3}\right)$ & $\begin{array}{l}\text { Age, gender, race, education, } \\
\text { marital status; BMI; smoking, } \\
\text { dietary intake, consumption of } \\
\text { alcoholic beverages; occupational } \\
\text { exposures }\end{array}$ & $\begin{array}{l}\text { Significant positive associations for } \mathrm{PM}_{2.5} \text { and } \\
\mathrm{NO}_{2} \text { in minimally and fully adjusted models. It } \\
\text { was non-significant for } \mathrm{O}_{3} . \mathrm{PM}_{2.5} \text {. Results were } \\
\text { only significant for men, never smokers, and } \\
\text { those with at least high school education. }\end{array}$ \\
\hline
\end{tabular}




\begin{tabular}{|c|c|c|c|c|c|c|}
\hline $\begin{array}{l}\text { First } \\
\text { author(year); } \\
\text { study location }\end{array}$ & $\begin{array}{l}\text { Design; number } \\
\text { cases/outcomes }\end{array}$ & Case definition & $\begin{array}{l}\text { Exposure } \\
\text { and metrics }\end{array}$ & assessment & Adjustment & Findings \\
\hline
\end{tabular}

Yeh et al. (2017); Ecologic study

Taiwan

Ancona et al. Cohort (outcome: 73)

(2015); Italy

Smith et al. Ecologic study

(2015); USA

(n)

Kung Ho et al. Case-control (case: 1641) (2010); Taiwan

\begin{abstract}
Mortality (data Kriging $\left(\mathrm{PM}_{2.5}\right) \quad$ Unclear source was unclear)

Mortality (death Dispersion modeling registration system $) \quad\left(\mathrm{PM}_{10} ; \mathrm{H}_{2} \mathrm{~S} ; \mathrm{SO}_{\mathrm{X}}\right)$

Une

Sex, age, education, occupation, $\mathrm{H}_{2} \mathrm{~S}$ exposure was significantly associated with civil status, area-based SEP bladder cancer mortality in women. No other index, outdoor $\mathrm{NO}_{2}$

Mortality (cancer Unclear $\left(\mathrm{PM}_{2.5} ; \mathrm{O}_{3}\right) \quad$ Unclear

registry)

In both sexes, $\mathrm{PM}_{2.5}$ was significantly associated with bladder cancer mortality. significant associations were found.

Increase in bladder cancer

mortality was associated with ozone days; but not with particulate matter air pollution days. On stratified analysis, the results were only significant for white male subjects.
\end{abstract} registration system)

Higher risk for the groups with high levels of petrol station density in their residential
Mortality (death Petrol station density

Marital status, urbanization

Mortality (death Monitoring stations $\left(\mathrm{SO}_{2}\right.$ : Marital status, urbanization registration system) $\left.\quad \mathrm{NO}_{2} ; \mathrm{PM}_{10} ; \mathrm{O}_{3} ; \mathrm{CO}\right)$ municipality. No statistically significant exposure-response trend.

A significant positive association between the levels of air pollution and bladder cancer mortality.

Liu et
Taiwan

883

884 BMI: body mass index; LUR: land use regression; PM: particulate matter; OR: odds ratio; $\mathrm{NO}_{2}$ : nitrogen dioxide; $\mathrm{O}_{3}$ : ozone; CO:

885 carbon monoxide; $\mathrm{SO}_{2}$ : Sulphur dioxide; $\mathrm{H}_{2} \mathrm{~S}$ : hydrogen sulfide; $\mathrm{PM}_{10}$ : particulate matters with diameter less than 10 micrometers;

886 SEP: socio-economic position

$887 \quad$ \$: for each outcome, studies are ordered chronologically from most recent to older 
889 Table 2. Summary of finding for the association between exposure to air pollution and kidney and urinary system cancer risk

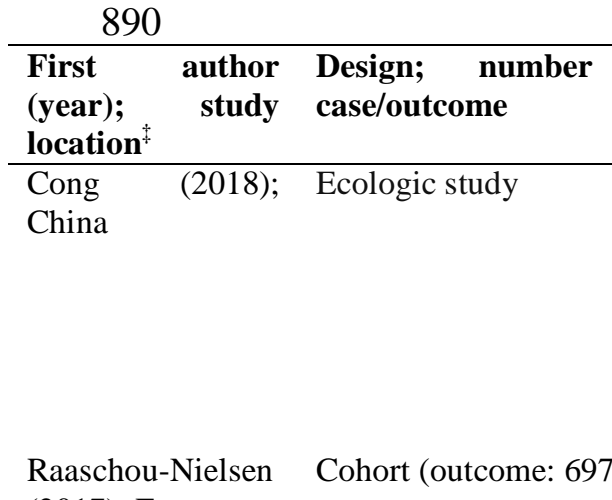

(2017); Europe

Raaschou-Nielsen Cohort (outcome: 95)

(2011); Denmark

Turner

(2017); Cohort (outcome: 927)

USA

\section{of Case definition}

Kidney

Kidney

incidence

registry)

(cancer

ancer

waste gas, other waste

gas, $\mathrm{SO}_{2}$, and soot)
Kidney incidence registry)

Kidney incidence registry) cancer LUR $\left(\mathrm{PM}_{10} ; \mathrm{PM}_{2.5} ; \mathrm{PM}_{2.5}\right.$ Age, sex, calendar time; smoking, (cancer absorbance; $\mathrm{NO}_{2} ; \mathrm{NO}_{\mathrm{x}} ;$ occupation, employment, and traffic intensity; PM education; area-level socioelements; organic carbon economic status in $\mathrm{PM}$ )

cancer LUR $\left(\mathrm{NO}_{\mathrm{x}}\right)$, presence of a BMI, smoking, hypertension,

(cancer major road within $50 \mathrm{~m}$, education, occupation Per $10^{4}$ vehicle $\mathrm{km} /$ day within $200 \mathrm{~m}$
Higher HR in association with higher $\mathrm{PM}_{2.5}$ concentration and $\mathrm{PM}_{25}$ absorbance. $\mathrm{HR}$ of $\mathrm{NO}_{\mathrm{x}}$ and traffic density on the nearest street were slightly above one. Effect estimates in nonmovers were slightly stronger than movers.

A significant increase in kidney cancer risk in crude models, but disappeared in the adjusted model.
Kidney cancer $\quad$ LUR $\left(\mathrm{PM}_{2.5} ; \mathrm{NO}_{2} ; \mathrm{O}_{3}\right)$ mortality (Cause of death from the questionnaire)

Kidney cancer Dispersion mortality (registry of $\left(\mathrm{PM}_{10} ; \mathrm{H}_{2} \mathrm{~S} ; \mathrm{SO}_{\mathrm{X}}\right)$ causes of death)

try of

Age, gender, race, education, Significant positive associations of $\mathrm{PM}_{2.5}$ in marital status; BMI; smoking, minimally and fully adjusted models. $\mathrm{PM}_{25}$ dietary intake, consumption of results were only significant for men, never alcoholic beverages; occupational smokers, and those with at least high school exposures education.
Sex, age, education, occupation, No significant associations were found. civil status, area-based SEP index, and outdoor $\mathrm{NO}_{2}$




\begin{tabular}{|c|c|c|c|c|c|c|}
\hline $\begin{array}{lr}\text { First } & \text { author } \\
\text { (year); } & \text { study } \\
\text { location } & \end{array}$ & $\begin{array}{l}\text { Design; number of } \\
\text { case/outcome }\end{array}$ & Case definition & $\begin{array}{l}\text { Exposure } \\
\text { and metrics }\end{array}$ & assessment & Adjustment & Findings \\
\hline $\begin{array}{l}\text { Cohen et al. } \\
\text { (2018); Israel }\end{array}$ & Cohort (outcome: 74) & $\begin{array}{l}\text { Urinary tract cancer } \\
\text { incidence (linked to } \\
\text { the National Cancer } \\
\text { Registry) }\end{array}$ & LUR $\left(\mathrm{NO}_{\mathrm{X}}\right)$ & & $\begin{array}{l}\text { Sex, smoking, neighborhood } \\
\text { socioeconomic status, ethnicity, } \\
\text { hypertension, diabetes, chronic } \\
\text { heart and renal failure, } \\
\text { hemoglobin levels }\end{array}$ & $\begin{array}{l}\text { Non-significant and small positive association } \\
\text { was found. }\end{array}$ \\
\hline $\begin{array}{l}\text { Wong et al. } \\
(2016) ; \quad \text { Hong- } \\
\text { Kong }\end{array}$ & Cohort (outcome: 155 ) & $\begin{array}{l}\text { Urinary cancer } \\
\text { mortality (data } \\
\text { linkage with death } \\
\text { registration system) }\end{array}$ & $\operatorname{LUR}\left(\mathrm{PM}_{2.5}\right)$ & & $\begin{array}{l}\text { Age, sex, BMI, smoking, } \\
\text { exercise, education, personal } \\
\text { monthly expenditure, percentage } \\
\text { of older subjects, the percentage } \\
\text { with tertiary education, monthly } \\
\text { domestic household income, } \\
\text { percentage of smokers, the } \\
\text { ground radon level }\end{array}$ & $\begin{array}{l}\text { No significant association was found neither in } \\
\text { all subjects nor in stratified groups by sex and } \\
\text { smoking status. }\end{array}$ \\
\hline
\end{tabular}

892

893 BMI: body mass index; LUR: land use regression; HR: hazard ratio; PM: particulate matter; OR: odds ratio; NO 2 : nitrogen dioxide;

$894 \mathrm{O}_{3}$ : ozone; $\mathrm{CO}$ : carbon monoxide; $\mathrm{SO}_{2}$ : Sulphur dioxide; $\mathrm{H}_{2} \mathrm{~S}$ : hydrogen sulfide; $\mathrm{PM}_{10}$ : particulate matters with diameter less than 10

895 micrometers; SEP: socio-economic position

897 studies are ordered from

most recent to older 
Table 3. Newcastle-Ottawa Scale (NOS) score for the cohort studies on the association between air pollution exposure and bladder,

899 kidney, and urinary cancer risk

\begin{tabular}{|c|c|c|c|c|c|c|c|c|c|c|}
\hline Outcome & Study (first author and year) & Representativeness & $\begin{array}{l}\text { Selection } \\
\text { of non- } \\
\text { cohort }\end{array}$ & $\begin{array}{l}\text { Exposure } \\
\text { ascertainment }\end{array}$ & $\begin{array}{l}\text { No } \\
\text { outcome } \\
\text { at the } \\
\text { start }\end{array}$ & Comparability & $\begin{array}{l}\text { Outcome } \\
\text { assessment }\end{array}$ & $\begin{array}{l}\text { Follow- } \\
\text { up time }\end{array}$ & $\begin{array}{l}\text { Follow- } \\
\text { up } \\
\text { adequacy }\end{array}$ & $\begin{array}{l}\text { NOS } \\
\text { score }\end{array}$ \\
\hline \multirow{7}{*}{$\begin{array}{l}\text { Bladder } \\
\text { cancer }\end{array}$} & Cohen et al. (2018) & 0 & 1 & 1 & 1 & 1 & 1 & 1 & 1 & 7 \\
\hline & Turner et al. (2017) & 1 & 1 & 1 & 1 & 2 & 1 & 1 & 0 & 8 \\
\hline & Collarile et al. (2017) & 1 & 0 & 1 & 0 & 0 & 1 & 0 & 0 & 3 \\
\hline & Raaschou Nielsen et al. (2011) & 1 & 1 & 1 & 1 & 1 & 1 & 1 & 1 & 8 \\
\hline & Pedersen et al. (2016) & 1 & 1 & 1 & 1 & 2 & 1 & 1 & 1 & 9 \\
\hline & Ancona et al. (2015) & 1 & 1 & 1 & 0 & 1 & 1 & 1 & 0 & 6 \\
\hline & Visser et al. (2004) & 1 & 1 & 1 & 1 & 0 & 1 & 0 & 0 & 5 \\
\hline \multirow{4}{*}{$\begin{array}{l}\text { Kidney } \\
\text { cancer }\end{array}$} & Turner et al. (2017) & 1 & 1 & 1 & 1 & 2 & 1 & 1 & 0 & 8 \\
\hline & Raaschou Nielsen et al. (2011) & 1 & 1 & 1 & 1 & 1 & 1 & 1 & 1 & 8 \\
\hline & Ancona et al. (2015) & 1 & 1 & 1 & 0 & 1 & 1 & 1 & 0 & 6 \\
\hline & Pedersen et al. (2016) & 1 & 1 & 1 & 1 & 2 & 1 & 1 & 1 & 9 \\
\hline \multirow{2}{*}{$\begin{array}{l}\text { Urinary tract } \\
\text { cancer }\end{array}$} & Cohen et al. (2018) & 0 & 1 & 1 & 1 & 1 & 1 & 1 & 1 & 7 \\
\hline & Wong et al. (2016) & 1 & 1 & 1 & 1 & 2 & 1 & 1 & 1 & 9 \\
\hline
\end{tabular}

900

901 
902 Table 4. Newcastle-Ottawa Scale (NOS) score for the case-control studies on the association between air pollution exposure and

903 bladder, kidney, and urinary cancer risk

904

905

\begin{tabular}{|c|c|c|c|c|c|c|c|c|c|c|}
\hline Outcome & Study (first author and year) & $\begin{array}{l}\text { Case } \\
\text { definitio } \\
\mathrm{n}\end{array}$ & $\begin{array}{l}\text { Representati } \\
\text { veness }\end{array}$ & $\begin{array}{l}\text { Control } \\
\text { selection }\end{array}$ & $\begin{array}{l}\text { Control } \\
\text { definition }\end{array}$ & $\begin{array}{l}\text { Compara } \\
\text { bility }\end{array}$ & $\begin{array}{l}\text { Exposure } \\
\text { assessment }\end{array}$ & $\begin{array}{l}\text { Same } \\
\text { exposure } \\
\text { method }\end{array}$ & $\begin{array}{l}\text { Response } \\
\text { rate }\end{array}$ & NOS score \\
\hline Bladder & Castano-Vinyals et al. (2008) & 1 & 0 & 0 & 1 & 2 & 0 & & 0 & 5 \\
\hline \multirow[t]{3}{*}{ cancer } & Liu et al. (2009) & 0 & 1 & 0 & 1 & 0 & 1 & & 0 & 4 \\
\hline & Ho et al. (2010) & 0 & 1 & 1 & 1 & 0 & 0 & & 0 & 4 \\
\hline & Turner et al. (2019) & 1 & 0 & 0 & 1 & 2 & 1 & & 0 & 6 \\
\hline
\end{tabular}

906

907 


\begin{tabular}{|c|c|c|c|c|c|c|c|}
\hline $\begin{array}{llll}\begin{array}{l}\text { Reference } \\
\text { (year) }\end{array} & \text { first author } \\
\end{array}$ & Site & Outcome & Pollutant & Population & Exposure categories $^{\neq}$ & $\begin{array}{l}\text { Type of } \\
\text { effect size }\end{array}$ & Point estimate (95\% CI) \\
\hline Al-ahmadi et al. (2013) & Bladder & Incidence & $\mathrm{NO}_{2}$ & All & Unclear & CIR & 0.22 (Unclear) \\
\hline Collarile et al. (2017) & Bladder & Incidence & $\mathrm{NO}_{2}$ & Male & $\leq 16.9$ vs $16.9-19.6 ;[10,80-25,50]$ & IRR & $1.07(0.86: 1.33)$ \\
\hline Collarile et al. (2017) & Bladder & Incidence & $\mathrm{NO}_{2}$ & Female & $\leq 16.9$ vs $16.9-19.6 ;[10,80-25,50]$ & IRR & $1.02(0.68: 1.54)$ \\
\hline Collarile et al. (2017) & Bladder & Incidence & $\mathrm{NO}_{2}$ & Male & $\leq 16.9$ vs $>19.6 ;[10,80-25,50]$ & IRR & $1.04(0.84: 1.30)$ \\
\hline Collarile et al. (2017) & Bladder & Incidence & $\mathrm{NO}_{2}$ & Female & $\leq 16.9$ vs $>19.6 ;[10,80-25,50]$ & IRR & 1.53 (1.03: 2.29) \\
\hline Pedersen et al. (2016) & Bladder & Incidence & $\mathrm{NO}_{2}$ & All & Per $10 \mu \mathrm{g} . \mathrm{m}^{-3} ; 25,68(14,29) ;[5,20-53,20]$ & HR & $0.98(0.89: 1.08)$ \\
\hline Turner et al. (2019) & Bladder & Incidence & $\mathrm{NO}_{2}$ & All & Per $14.2 \mu \mathrm{g} . \mathrm{m}^{-3} ; 28,60(10,20) ;[1,10-58,60]$ & OR & $0.97(0.84: 1.13)$ \\
\hline Cohen et al. (2018) & Bladder & Incidence & $\mathrm{NO}_{\mathrm{x}}$ & All & Per 10 ppb; 19.5; [2,3- 79,7] & HR & $1.07(0.83: 1.37)$ \\
\hline Pedersen et al. (2016) & Bladder & Incidence & $\mathrm{NO}_{\mathrm{x}}$ & All & Per $20 \mu \mathrm{g} \cdot \mathrm{m}^{-3} ; 47,56(28,45) ;[8,7-96,4]$ & HR & $0.99(0.91: 1.09)$ \\
\hline Raaschou-Nielsen (2011) & Bladder & Incidence & $\mathrm{NO}_{\mathrm{x}}$ & All & Per $100 \mu \mathrm{g} . \mathrm{m}^{-3} ; 28.4 ;[14,8-69,4]$ & IRR & $1.32(0.80: 2.19)$ \\
\hline Collarile et al. (2017) & Bladder & Incidence & $\mathrm{PM}_{10}$ & Male & $\leq 40.6$ vs $40.6-51.9 ;[19.6-107.1]$ & IRR & $1.10(0.89: 1.36)$ \\
\hline Collarile et al. (2017) & Bladder & Incidence & $\mathrm{PM}_{10}$ & Female & $\leq 40.6$ vs $40.6-51.9 ;[19.6-107.1]$ & IRR & $1.16(0.78: 1.71)$ \\
\hline Collarile et al. (2017) & Bladder & Incidence & $\mathrm{PM}_{10}$ & Male & $\leq 40.6$ vs $>51.9 ;[19.6-107.1]$ & IRR & $1.00(0.80: 1.25)$ \\
\hline Collarile et al. (2017) & Bladder & Incidence & $\mathrm{PM}_{10}$ & Female & $\leq 40.6$ vs $>51.9 ;[19.6-107.1]$ & IRR & $1.21(0.80: 1.84)$ \\
\hline Eitan et al. (2010) & Bladder & Incidence & $\mathrm{PM}_{10}$ & Male & Unclear ; [27,8-41.2] & RR & $0.82(0.37: 1.07)$ \\
\hline Eitan et al. (2010) & Bladder & Incidence & $\mathrm{PM}_{10}$ & Female & Unclear ; [28,8-41.3] & RR & $1.70(0.25: 5.11)$ \\
\hline Pedersen et al. (2016) & Bladder & Incidence & $\mathrm{PM}_{10}$ & All & Per $10 \mu$ g.m-3; 23,79 (11,82); [13,5- 46,4] & HR & $0.92(0.58: 1.48)$ \\
\hline Pedersen et al. (2016) & Bladder & Incidence & $\mathrm{PM}_{2.5}$ & All & Per $5 \mu$ g.m-3; 14,62 (7,48); [7,1- 30,1] & HR & $0.86(0.63: 1.18)$ \\
\hline Turner et al. (2019) & Bladder & Incidence & $\mathrm{PM}_{2.5}$ & All & Per $5.9 \mu \mathrm{g} / \mathrm{m} 3 ; 15.8$ (3.89); [7- 25.6] & OR & $1.06(0.71: 1.60)$ \\
\hline Wang et al. (2019) & Bladder & Incidence & $\mathrm{PM}_{2.5}$ & All & Unclear & $\begin{array}{l}\text { Correlation } \\
\text { coefficient }\end{array}$ & 0.85 (Unclear) \\
\hline Collarile et al. (2017) & Bladder & Incidence & $\mathrm{SO}_{2}$ & Female & $\leq 34.6$ vs $34.6-37.5 ;[27,5-85]$ & IRR & $1.19(0.80: 1.78)$ \\
\hline Collarile et al. (2017) & Bladder & Incidence & $\mathrm{SO}_{2}$ & Female & $\leq 34.6$ vs $>37.5 ;[27,5-85]$ & IRR & $1.39(0.93: 2.08)$ \\
\hline Collarile et al. (2017) & Bladder & Incidence & $\mathrm{SO}_{2}$ & Male & $\leq 34.6$ vs $34.6-37.5 ;[27,5-85]$ & IRR & $1.16(0.94: 1.44)$ \\
\hline Collarile et al. (2017) & Bladder & Incidence & $\mathrm{SO}_{2}$ & Male & $\leq 34.6$ vs $>37.5 ;[27,5-85]$ & IRR & $1.02(0.82: 1.27)$ \\
\hline Eitan et al. (2010) & Bladder & Incidence & $\mathrm{SO}_{2}$ & Male & Unclear ; [1,8- 14,7] & RR & $1.02(0.30: 2.25)$ \\
\hline
\end{tabular}




\begin{tabular}{|c|c|c|c|c|c|c|c|}
\hline Eitan et al. (2010) & Bladder & Incidence & $\mathrm{SO}_{2}$ & Female & Unclear; [1,8- 14,7] & $\mathrm{RR}$ & $1.15(0.22: 5.27)$ \\
\hline Radespiel $\square$ Tröger et al.(2018) & Bladder & Incidence & $\mathrm{PM}_{10}$ & Male & Per $10 \mu$ g.m-3 ; 19.2 [12.7- 26.6] & $\mathrm{RR}$ & $1.19(1.01-1.41)$ \\
\hline Radespiel $\square$ Tröger et al.(2018) & Bladder & Incidence & $\mathrm{PM}_{10}$ & Female & Per $10 \mu$ g.m-3; 19.2 [12.7- 26.6] & $\mathrm{RR}$ & $1.26(1.09-1.47)$ \\
\hline Liu et al. (2008) & Bladder & Mortality & $\mathrm{NO} 2$ & All & $\leq 20.99$ vs $21.19-26.87$ ppb; Unclear & $\begin{array}{l}\text { Unadjusted } \\
\text { OR }\end{array}$ & 1.41 (1.08: 1.84) \\
\hline Liu et al. (2008) & Bladder & Mortality & $\mathrm{NO}_{2}$ & All & $\leq 20.99$ vs $27.33-44.85 \mathrm{ppb}$; Unclear & $\begin{array}{l}\text { Unadjusted } \\
\text { OR }\end{array}$ & $1.73(1.27-2.36)$ \\
\hline Turner et al. (2017) & Bladder & Mortality & $\mathrm{NO}_{2}$ & All & Per $6.5 \mathrm{ppb} ; 11,6(5,1) ;[1-37,6]$ & HR & 1.03 (0.94: 1.12) \\
\hline Liu et al. (2009) & Bladder & Mortality & $\mathrm{O}_{3}$ & All & $\leq 22.41$ vs $22.42-25.06 \mathrm{ppb}$ & $\begin{array}{l}\text { Unadjusted } \\
\text { OR }\end{array}$ & $0.88(0.68: 1.16)$ \\
\hline Liu et al. (2009) & Bladder & Mortality & $\mathrm{O}_{3}$ & All & $\leq 22.41$ vs $25.11-35.70 \mathrm{ppb}$ & $\begin{array}{l}\text { Unadjusted } \\
\text { OR }\end{array}$ & $1.07(0.82: 1.39)$ \\
\hline Turner et al. (2017) & Bladder & Mortality & $\mathrm{O}_{3}$ & All & Per 6.9 ppb; 38,2 (4); [26,7- 59,3] & HR & $1.03(0.93: 1.14)$ \\
\hline Smith et al. (2016) & Bladder & Mortality & $\mathrm{O}_{3}$ & All & Unclear & $\begin{array}{l}\text { Regression } \\
\text { coefficient }\end{array}$ & $0.01(0.01: 0.02)$ \\
\hline Ancona et al. (2015) & Bladder & Mortality & $\mathrm{PM}_{10}$ & Male & Per $0.027 \mathrm{ng} ; 0,02(0,02) ;[0,02-0,04]$ & HR & $1.05(0.70: 1.57)$ \\
\hline Ancona et al. (2015) & Bladder & Mortality & $\mathrm{PM}_{10}$ & Female & Per $0.027 \mathrm{ng} ; 0,02(0,02) ;[0,02-0,04]$ & HR & $1.53(0.70: 3.36)$ \\
\hline Liu et al. (2009) & Bladder & Mortality & $\mathrm{PM}_{10}$ & All & $\leq 52.80$ vs $53.04-71.72 ;$ Unclear & $\begin{array}{l}\text { Unadjusted } \\
\text { OR }\end{array}$ & $1.08(0.83: 1.41)$ \\
\hline Liu et al. (2009) & Bladder & Mortality & $\mathrm{PM}_{10}$ & & $\leq 52.80$ vs $72.24-90.29 ;$ Unclear & $\begin{array}{l}\text { Unadjusted } \\
\text { OR }\end{array}$ & 1.39 (1.06: 1.83) \\
\hline Smith et al. (2016) & Bladder & Mortality & $\mathrm{PM}_{2.5}$ & All & Unclear & $\begin{array}{l}\text { Regression } \\
\text { coefficient }\end{array}$ & $-0.01(-0.02: 0.00)$ \\
\hline Turner et al. (2017) & Bladder & Mortality & $\mathrm{PM}_{2.5}$ & All & 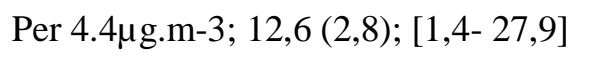 & HR & 1.13 (1.03: 1.23) \\
\hline Wang et al. (2019) & Bladder & Mortality & $\mathrm{PM}_{2.5}$ & All & Unclear & $\begin{array}{l}\text { Correlation } \\
\text { coefficient }\end{array}$ & -0.42 (Unclear) \\
\hline Yeh et al. (2017) & Bladder & Mortality & $\mathrm{PM}_{2.5}$ & All & Per $1 \mu$ g.m-3; Unclear & $\begin{array}{l}\text { Regression } \\
\text { coefficient }\end{array}$ & 0.04 (0.04: 0.04) \\
\hline Liu et al. (2009) & Bladder & Mortality & $\mathrm{SO}_{2}$ & All & $\leq 4.32$ vs 4.39-6.09; Unclear & $\begin{array}{l}\text { Unadjusted } \\
\text { OR }\end{array}$ & 1.42 (1.10: 1.85) \\
\hline Liu et al. (2009) & Bladder & Mortality & $\mathrm{SO}_{2}$ & All & $\leq 4.32$ vs $6.49-17.87 ;$ Unclear & $\begin{array}{l}\text { Unadjusted } \\
\text { OR }\end{array}$ & 1.73 (1.32: 2.27) \\
\hline
\end{tabular}

912 For exposure categories: specified risk increase per how much of pollutant

$913+$ : mean (SD); numbers in bracket are a range [lower range- upper range] 
Table 6. Reported associations between exposure to outdoor air pollution exposure and kidney and urinary cancer risk

\section{Reference: first author (year)}

Raaschou-Nielsen (2011)

Raaschou-Nielsen (2017)

Raaschou-Nielsen (2017)

Raaschou-Nielsen (2017)

Raaschou-Nielsen (2017)

Turner et al. (2017)

Turner et al. (2017)

Cohen et al. (2018)

Wong et al. (2016)

Outcome Pollutant Population Exposure categories

Incidence $\mathrm{NO}$

\section{Kidney}

Kidney

Kidney

Kidney

Kidney

Kidney

Kidney

Urinary tract

Incidence $\mathrm{NO}_{\mathrm{x}} \quad$ All

Urinary tract
Incidence $\mathrm{NO}_{\mathrm{x}}$

All

Incidence $\mathrm{NO}_{\mathrm{x}} \quad$ All

Incidence $\mathrm{PM}_{10} \quad$ All

Incidence $\mathrm{PM}_{2.5} \quad$ All

Incidence $\mathrm{NO}_{2} \quad$ All

Mortality $\mathrm{O}_{3} \quad$ All

Mortality $\mathrm{PM}_{2.5} \quad$ All

Per 6.9 ppb; 38,2 (4); [26,7- 59,3] HR

Mortality $\mathrm{PM}_{2.5} \quad$ All

Per $100 \mu$ g.m-3 ; Unclear

Per $20 \mu \mathrm{g} . \mathrm{m}-3$; 19.5; [2,3- 79,7]

Per $5 \mu$ g.m-3; 13,94 (7,8); [7,1- 30,1] HR

Per $10 \mu$ g.m-3; 24,32 (14,33); [5,2- 53,2] HR

Per 4.4 g.m-3; 12,6 (2,8); [1,4- 27,9] HR

Per 10 ppb; 19.5; [2,3- 79,7]

Type of effe

RR



Point estimate (95\% CI)

$1.73(0.89 ; 3.73)$

1.29 (0.85: 1.96)

1.57 (0.81: 3.01)

1.04 (0.92: 1.19)

0.97 (0.86: 1.09)

1.14 (1.03: 1.27)

1.07 (0.88: 1.3)

0.98 (0.58: 1.64)
915

916

917

918

919

920

921

922

923

924

925

926

927

928

929

930

exposure categories: specified risk increase

₹: mean (sd); numbers in bracket are a range [lower range- upper range] 
Table S1. The sample search algorithm used for literature search on outdoor air pollution exposure (as an exposure) and selected urological cancer incidence and/or mortality (as an outcome) on PubMed (https://www.ncbi.nlm.nih.gov/pubmed/). Last updated on June 15, 2019.

\begin{tabular}{|c|c|c|}
\hline \# & Search query & $\begin{array}{l}\text { Numbers of items } \\
\text { found }\end{array}$ \\
\hline \multirow[t]{3}{*}{1} & 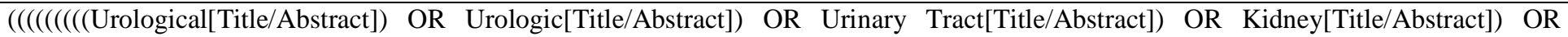 & 1044802 \\
\hline & Renal[Title/Abstract]) $\quad$ OR $\quad$ Ureteral[Title/Abstract]) $\quad$ OR & \\
\hline & URETHRA[Title/Abstract]) OR Bladder[Title/Abstract] & \\
\hline 2 & (((tumor[Title/Abstract]) OR neoplasm[Title/Abstract]) OR cancer[Title/Abstract]) OR malignancy[Title/Abstract] & 2338139 \\
\hline 3 & 1 and 2 & 147101 \\
\hline \multirow[t]{2}{*}{4} & $((((($ Kidney Neoplasms"[Mesh]) $\quad$ OR "Pelvic Neoplasms"[Mesh]) $\quad$ OR "Ureteral Neoplasms"[Mesh]) $\quad$ OR "Urinary Bladder & 135254 \\
\hline & Neoplasms"[Mesh]) OR "Urologic Neoplasms"[Mesh]) OR "Urethral Neoplasms"[Mesh] & \\
\hline 5 & ((("cancer incidence"[Title/Abstract]) OR "incidence of cancer"[Title/Abstract]) OR "cancer mortality"[Title/Abstract]) & 32351 \\
\hline 6 & 3 or 4 or 5 & 244602 \\
\hline \multirow[t]{5}{*}{7} & (((((((()(((((((pm2.5[Title/Abstract]) OR pm10[Title/Abstract]) OR o3[Title/Abstract]) OR ozone[Title/Abstract]) OR no2[Title/Abstract]) & 200074 \\
\hline & OR "nitrogen dioxide"[Title/Abstract]) $\quad$ OR "carbon monoxide"[Title/Abstract]) $\quad$ OR $\quad$ so2[Title/Abstract]) OR "Sulfur & \\
\hline & dioxide"[Title/Abstract]) OR "Sulphur dioxide"[Title/Abstract]) OR "air pollutants"[Title/Abstract]) OR "air pollution"[Title/Abstract]) OR & \\
\hline & "particulate matter"[Title/Abstract]) OR "Ambient air"[Title/Abstract]) OR "Air quality"[Title/Abstract])) OR ((((("Air Pollution"[Mesh]) & \\
\hline & OR "Particulate Matter"[Mesh]) OR "Air Pollutants" [Mesh]) OR "Vehicle Emissions"[Mesh]) OR "Traffic-Related Pollution"[Mesh])) & \\
\hline 8 & 6 and 7 & 1513 \\
\hline
\end{tabular}


Table S2. Inclusion and exclusion criteria based on PECOS (population, exposure, comparison, outcome and study type) for a systematic review on the association between outdoor air pollution exposure and risk of selected urological cancers

\begin{tabular}{|c|c|c|}
\hline Decision & $\begin{array}{l}\text { Population } \\
\end{array}$ & Exposure \\
\hline Inclusion & Human; Adult & $\begin{array}{l}\text { Ambient air pollution including } \\
\text { a) specific pollutants (e.g. } \mathrm{PM}_{10} ; \mathrm{PM}_{2.5} ; \\
\mathrm{SO}_{2} ; \mathrm{NO}_{2} ; \mathrm{O}_{3} ; \mathrm{CO} ; \mathrm{NO}_{\mathrm{x}} \text { ) } \\
\text { b) proxies (traffic; proximity index; ...) }\end{array}$ \\
\hline
\end{tabular}

$\begin{array}{ll}\text { Exclusion } & \text { Children; Animal } \\ & \text { Occupational }\end{array}$ cohorts

Nom

\section{Comparison}

ot applicable

$\mathrm{SO}_{2} ; \mathrm{NO}_{2} ; \mathrm{O}_{3} ; \mathrm{CO} ; \mathrm{NO}_{\mathrm{x}}$

\section{$\begin{array}{ll}\text { Exclusion } & \text { Children; Animal } \\ & \text { Occupational }\end{array}$}

Occupational /Industrial

air pollution exposure; geothermal and volcanic air pollution exposure; radioactive pollutants; radon; asbestos; pesticides; indoor air pollution; smoking-related products

$\begin{array}{ll}\text { Outcome } & \text { Type of study } \\ \text { Selected urological } & \text { Prospective and } \\ \text { cancers } & \text { retrospective } \\ \text { incidence/mortality } & \text { cohort; } \\ \text { (including kidney; case-control; } \\ \text { bladder; urinary tract) } & \text { ecologic studies }\end{array}$

Urinary cancer hospital Time series; caseadmission; other report; reviews; urological cancers in-vitro studies 
944

Table S3: GRADE assessment for the association between exposure to $\mathbf{P M}_{10}$ and risk of bladder cancer incidence

\begin{tabular}{|c|c|c|}
\hline Domains & Assessment & Downgrading/ upgrading \\
\hline Indirectness & $\begin{array}{l}\text { The exposure to air pollution allocated differently across different studies to the } \\
\text { participants (LUR, dispersion modeling, and interpolation). }\end{array}$ & No change \\
\hline Publication bias & Given the comprehensive search, it seems little even no publication bias. & Unclear \\
\hline Dose-response trend & One out of four studies analyzed a trend, however, found no linear trend. & No increase \\
\hline Magnitude of associations & In all studies and reported associations, the magnitude of the effect sizes was below 1.4. & No increase \\
\hline Residual confounding & Two ecologic studies suffering from the risk of exposure misclassifications. & No increase \\
\hline Overall judgment & Very low & \\
\hline
\end{tabular}

$$
945
$$

946 
Table S4: GRADE assessment for the association between exposure to $\mathrm{PM}_{10}$ and risk of bladder cancer mortality

\begin{tabular}{|c|c|c|}
\hline Domains & Assessment & Downgrading/ upgrading \\
\hline Start level & One cohort, one case-control study & High \\
\hline Inconsistency & The direction of the effect sizes are not opposite; however, the magnitudes are different. & No change \\
\hline Indirectness & $\begin{array}{l}\text { All of the studies conducted on the general population and the outcomes drawn from } \\
\text { death registries. }\end{array}$ & No change \\
\hline Dose-response trend & One of the studies reported a dose-response association. & Upgrade \\
\hline $\begin{array}{l}\text { Magnitude of } \\
\text { associations }\end{array}$ & Two studies reported effect sizes with a magnitude below 1.4 . & No increase \\
\hline Residual confounding & $\begin{array}{l}\text { One of the studies used readings from monitoring stations for exposure allocation. Also, } \\
\text { one study just reported a crude association. }\end{array}$ & No increase \\
\hline Overall judgment & Low & \\
\hline
\end{tabular}


Table S5: GRADE assessment for the association between exposure to $\mathrm{PM}_{2.5}$ and risk of bladder cancer incidence

\begin{tabular}{|c|c|c|}
\hline Domains & Assessment & Downgrading/ upgrading \\
\hline Start level & One cohort, one case-control, and one ecologic study & High \\
\hline Risk of bias & $\begin{array}{l}\text { The cohort study summarized the results of several other cohorts and has a good NOS } \\
\text { score. However, the case-control suffering from representativeness and appropriate } \\
\text { selection of controls. }\end{array}$ & No change \\
\hline Inconsistency & $\begin{array}{l}\text { The direction and magnitude of the effect sizes across the studies were inconsistent. The } \\
\text { point estimates were varying and confidence intervals were partially overlapped. }\end{array}$ & Downgrade \\
\hline Indirectness & $\begin{array}{l}\text { Exposure to air pollution, population, and outcome were in accordance with the review } \\
\text { aim. }\end{array}$ & No change \\
\hline Imprecision & $\begin{array}{l}\text { The point estimates and confidence intervals were not consistent. The number of studies } \\
\text { is not sufficient. }\end{array}$ & Downgrade \\
\hline Publication bias & $\begin{array}{l}\text { Given the comprehensive search, it seems little even no publication bias. However, we } \\
\text { were not able to test it objectively. }\end{array}$ & Unclear \\
\hline Dose-response trend & None of the studies reported the dose-response. & No increase \\
\hline $\begin{array}{ll}\text { Magnitude } & \text { of } \\
\text { associations } & \end{array}$ & In all studies and reported association, the magnitude of the effect sizes was below 1.4. & No increase \\
\hline Residual confounding & No sign of exposure misclassification. & No increase \\
\hline Overall judgment & Very Low & \\
\hline
\end{tabular}

948

949 
Table S6: GRADE assessment for the association between exposure to $\mathrm{PM}_{2.5}$ and risk of bladder cancer mortality

\begin{tabular}{|c|c|c|}
\hline Domains & Assessment & Downgrading/ upgrading \\
\hline Start level & One cohort, three ecologic studies & Low \\
\hline Risk of bias & $\begin{array}{l}\text { Most of the studies were ecologic and the source of outcome data was not clear in one of } \\
\text { them. Due to the nature of ecologic studies, the risk of bias was high. }\end{array}$ & Downgrade \\
\hline Inconsistency & Direction and the value of the effect sizes were different across studies. & Downgrade \\
\hline Indirectness & $\begin{array}{l}\text { The methods of exposure assessment and allocation across the studies were different. } \\
\text { However, the population and outcome were similar. }\end{array}$ & No change \\
\hline Imprecision & The point estimates and confidence intervals were not consistent. & Downgrade \\
\hline Publication bias & $\begin{array}{l}\text { Given the comprehensive search, it seems little even no publication bias. However, we were } \\
\text { not able to check it objectively. }\end{array}$ & Unclear \\
\hline Dose-response trend & None of the studies reported the dose-response trend. & No change \\
\hline $\begin{array}{l}\text { Magnitude of } \\
\text { associations }\end{array}$ & The magnitude of effect sizes was large enough to upgrade the level of evidence. & No change \\
\hline Residual confounding & Three studies used area-level measures of exposure. & No change \\
\hline Overall judgment & Very low & \\
\hline
\end{tabular}

950

951 
Table S7: GRADE assessment for the association between exposure to $\mathrm{NO}_{2}$ and risk of bladder cancer incidence

\begin{tabular}{|c|c|c|}
\hline Domains & Assessment & Downgrading/ upgrading \\
\hline Start level & Two cohorts, one case-control, and one ecologic study & High \\
\hline Risk of bias & $\begin{array}{l}\text { Three out of four studies suffering from different methodological issues including } \\
\text { representativeness of the population, control selection, or inadequate control of } \\
\text { confounding. Therefore, most of the information is coming from studies with a high risk } \\
\text { of bias. }\end{array}$ & Downgrade \\
\hline Inconsistency & $\begin{array}{l}\text { The point estimates were different and confidence intervals were partially overlapped. } \\
\text { The confidence intervals were reasonable except in the case of the ecologic study. }\end{array}$ & Downgrade \\
\hline Indirectness & $\begin{array}{l}\text { Exposure to air pollution allocated differently across the studies (LUR, dispersion } \\
\text { modeling, and ecologic approaches). However, in general, the population, exposure, and } \\
\text { exposure were in accordance with the PECO. }\end{array}$ & No change \\
\hline Imprecision & $\begin{array}{l}\text { Decision based on each side of the confidence intervals was associated to a different } \\
\text { judgment. }\end{array}$ & Downgrade \\
\hline Publication bias & $\begin{array}{l}\text { Given the comprehensive search and size of the sample in the published studies we } \\
\text { decided little even no publication bias. }\end{array}$ & Unclear \\
\hline $\begin{array}{l}\text { Dose-response } \\
\text { trend }\end{array}$ & $\begin{array}{l}\text { One out of four studies conducted the categorized analyses based on exposure intensity. } \\
\text { However, the observed trend in the groups was not similar in males and females. }\end{array}$ & No change \\
\hline $\begin{array}{l}\text { Magnitude } \\
\text { associations }\end{array}$ & $\begin{array}{l}\text { In all reported associations, the magnitude of the effect sizes was large enough to lead } \\
\text { to an upgrade of evidence. }\end{array}$ & No change \\
\hline $\begin{array}{l}\text { Residual } \\
\text { confounding }\end{array}$ & $\begin{array}{l}\text { In two out of four studies the confounding adjustment was not clear. We think } \\
\text { adjustment would decrease the observed strength of observed associations. }\end{array}$ & No change \\
\hline Overall judgment & Very low & \\
\hline
\end{tabular}

952

953 
Table S8: GRADE assessment for the association between exposure to $\mathrm{NO}_{2}$ and risk of bladder cancer mortality

\begin{tabular}{|c|c|c|}
\hline Domains & Assessment & Downgrading/ upgrading \\
\hline Start level & One cohort, one case-control study & High \\
\hline Risk of bias & $\begin{array}{l}\text { The case-control study suffering from different methodological issues including case } \\
\text { definition, control selection, unclear response rate, and inadequate control of } \\
\text { confounders. The cohort study suffering from the inadequacy of follow-up. }\end{array}$ & Downgrade \\
\hline Inconsistency & $\begin{array}{l}\text { The direction of effect sizes are similar for both studies, but the point estimates are } \\
\text { different. }\end{array}$ & No change \\
\hline Indirectness & $\begin{array}{l}\text { Both studies conducted on the general population and the outcomes drawn from } \\
\text { death registries. The exposure assessment in the case-control study was not as } \\
\text { precise as the cohort (it was based on station reading in the case-control study). }\end{array}$ & No change \\
\hline Imprecision & $\begin{array}{l}\text { The effect estimates in the case-control were precise. However, in the cohort study, } \\
\text { there was impreciseness in the reported effect sizes. }\end{array}$ & Downgrade \\
\hline Publication bias & $\begin{array}{l}\text { Given the comprehensive search, it seems little even no publication bias. However, } \\
\text { we were not able to systematically assess the publication bias by statistical tests or } \\
\text { visual plots. }\end{array}$ & Unclear \\
\hline Dose-response trend & One of the studies reported dose-response data. & Upgrade \\
\hline $\begin{array}{l}\text { Magnitude of } \\
\text { associations }\end{array}$ & In one case-control study, the magnitude of the effects was above 1.4 . & No increase \\
\hline Residual confounding & $\begin{array}{l}\text { Considering possible exposure misclassification in using monitoring stations readings } \\
\text { for exposure allocation, effect estimates would shift to null. }\end{array}$ & No increase \\
\hline Overall judgment & 40 & \\
\hline
\end{tabular}


Table S9: GRADE assessment for the association between exposure to $\mathrm{NO}_{\mathrm{x}}$ and risk of bladder cancer incidence

\begin{tabular}{|c|c|c|}
\hline Domains & Assessment & Downgrading/ upgrading \\
\hline Start level & Three cohort studies & High \\
\hline Risk of bias & $\begin{array}{l}\text { The overall risk of bias in all three cohorts was low. Adjustment for sex and age in one } \\
\text { of the cohorts and also representativeness of the population in another cohort were } \\
\text { problematic. }\end{array}$ & Downgrade \\
\hline Inconsistency & $\begin{array}{l}\text { The magnitude of the point estimate risks in the studies was different (ranged from } \\
0.99 \text { to 1.32). Two of cohorts reported an increase (even though at different } \\
\text { magnitude) and one other reported a trivial decrease (0.99) }\end{array}$ & Downgrade \\
\hline Indirectness & $\begin{array}{l}\text { The population of interest in one of the studies were from cardiac patients and did } \\
\text { not completely cover the population of interest in this study. }\end{array}$ & Downgrade \\
\hline Imprecision & $\begin{array}{l}\text { All three cohorts have reported this exposure-outcome association, but decide on } \\
\text { both sides of the confidence intervals will lead to a different judgment. }\end{array}$ & Downgrade \\
\hline Publication bias & $\begin{array}{l}\text { Given the comprehensive search, it seems little even no publication bias. However, } \\
\text { we were not able to systematically assess the publication bias by statistical tests or } \\
\text { visual plots. }\end{array}$ & Unclear \\
\hline Dose-response trend & No report. & No change \\
\hline $\begin{array}{l}\text { Magnitude of } \\
\text { associations }\end{array}$ & The magnitude of the observed effects was not large enough to leads to an upgrade. & No change \\
\hline Residual confounding & The risk of exposure misclassification is low in all three studies. & Upgrade \\
\hline Overall judgment & Very Low & \\
\hline
\end{tabular}

956

957 
Table S10: GRADE assessment for the association between exposure to $\mathrm{SO}_{2}$ and risk of bladder cancer incidence

\begin{tabular}{|c|c|c|}
\hline Domains & Assessment & Downgrading/ upgrading \\
\hline Start level & One cohort and one ecologic study & High \\
\hline Risk of bias & $\begin{array}{l}\text { The risk of bias in the cohort study was high. Also considering the low } \\
\text { quality of ecologic studies per se, the overall quality of methodological } \\
\text { issues is not satisfactory. }\end{array}$ & Downgrade \\
\hline Inconsistency & $\begin{array}{l}\text { The point estimate of the observed risk in studies was } 1.02 \text { to } 1.39 \\
\text { however all of them reported an increase in the risk. The confidence } \\
\text { intervals (especially in the ecologic study) are wide. }\end{array}$ & Downgrade \\
\hline Indirectness & $\begin{array}{l}\text { Given the ecologic allocation of exposure to the population in one of } \\
\text { the studies, there is a heterogeneity in the exposure assessment } \\
\text { methods. }\end{array}$ & Downgrade \\
\hline Imprecision & $\begin{array}{l}\text { The number of studies is limited }(n=2) \text {. The judgment will be changed } \\
\text { according to the selection of each side of the confidence interval. }\end{array}$ & Downgrade \\
\hline Publication bias & $\begin{array}{l}\text { Given the comprehensive search, it seems little even no publication } \\
\text { bias. However, we were unable to objectively evaluate the possible } \\
\text { publication bias. }\end{array}$ & Unclear \\
\hline Dose-response trend & No report. & No change \\
\hline Magnitude of associations & $\begin{array}{l}\text { In all reported associations the magnitude of the effect sizes was } \\
\text { below } 1.4 \text {. }\end{array}$ & No change \\
\hline Residual confounding & Not enough for upgrading. & No change \\
\hline Overall judgment & Very low & \\
\hline
\end{tabular}

958

959 
Table S11: GRADE assessment for the association between exposure to $\mathrm{O}_{3}$ and risk of bladder cancer mortality

\begin{tabular}{|c|c|c|}
\hline Domains & Assessment & Downgrading/ upgrading \\
\hline Start level & One cohort and one case-control and one ecologic & High \\
\hline Risk of bias & $\begin{array}{l}\text { The risk of bias in the case-control study was high due to no exact definition } \\
\text { of cases and controls. Follow-up time in the cohort was not sufficient. }\end{array}$ & Downgrade \\
\hline Inconsistency & $\begin{array}{l}\text { The magnitude of observed risk in the studies was } 0.88 \text { to } 1.07 \text {. The observed } \\
\text { effect sizes in the case-control study were opposite at different doses of } \\
\text { exposure. }\end{array}$ & Downgrade \\
\hline Indirectness & $\begin{array}{l}\text { The population and outcome were in accordance with the PECO. However, } \\
\text { the exposure assessment methods in the studies were different. }\end{array}$ & No change \\
\hline Imprecision & $\begin{array}{l}\text { The judgment will be changed according to the selection of each side of the } \\
\text { confidence intervals. }\end{array}$ & Downgrade \\
\hline Publication bias & $\begin{array}{l}\text { Given the comprehensive search, it seems little even no publication bias. } \\
\text { However, we were unable to objectively evaluate the possible publication } \\
\text { bias. }\end{array}$ & Unclear \\
\hline Dose-response trend & No report. & No change \\
\hline $\begin{array}{l}\text { Magnitude of } \\
\text { associations }\end{array}$ & $\begin{array}{l}\text { The magnitude of the observed effect sizes was not large enough to upgrade } \\
\text { the evidence. }\end{array}$ & No change \\
\hline Residual confounding & $\begin{array}{l}\text { A case-control study has used exposure data from monitoring stations, which } \\
\text { can introduce misclassification bias. }\end{array}$ & No change \\
\hline Overall judgment & $9+2$ & \\
\hline
\end{tabular}




\section{Highlights:}

- Few studies - ecological, case-control and cohorts - were eligible.

- Limitation issues of the studies prevented the meta-analysis realization.

- Positive association between air pollution and bladder and kidney cancer risk were showed.

- For bladder cancer, mortality evidences were stronger than the incidence.

- Future studies should be rigorous with adjustment, exposure assessment methods and follow-ups. 


\section{Declaration of interests}

$\bigotimes$ The authors declare that they have no known competing financial interests or personal relationships that could have appeared to influence the work reported in this paper.

$\square$ The authors declare the following financial interests/personal relationships which may be considered as potential competing interests: 